\title{
Friendship characteristics associated with adolescent friendship maintenance and dissolution
}

\author{
Rebecca A. Owens \\ West Virginia University
}

Follow this and additional works at: https://researchrepository.wvu.edu/etd

\section{Recommended Citation}

Owens, Rebecca A., "Friendship characteristics associated with adolescent friendship maintenance and dissolution" (2001). Graduate Theses, Dissertations, and Problem Reports. 693.

https://researchrepository.wvu.edu/etd/693

This Thesis is protected by copyright and/or related rights. It has been brought to you by the The Research Repository @ WVU with permission from the rights-holder(s). You are free to use this Thesis in any way that is permitted by the copyright and related rights legislation that applies to your use. For other uses you must obtain permission from the rights-holder(s) directly, unless additional rights are indicated by a Creative Commons license in the record and/ or on the work itself. This Thesis has been accepted for inclusion in WVU Graduate Theses, Dissertations, and Problem Reports collection by an authorized administrator of The Research Repository @ WVU. For more information, please contact researchrepository@mail.wvu.edu. 
Friendship Characteristics Associated with Adolescent Friendship

Maintenance and Dissolution

\title{
Rebecca A. Owens
}

Thesis submitted to the Eberly College of Arts and Sciences in partial fulfillment of the requirements

for the degree of

\author{
Master of Arts \\ in \\ Psychology
}

\author{
JoNell Strough, Ph.D., Chair \\ Katherine Karraker, Ph.D. \\ B. Kent Parker, Ph.D. \\ Department of Psychology
}
Morgantown, West Virginia 2001

Keywords: friendship quality, friendship dissolution, early adolescence 


\begin{abstract}
Friendship Characteristics Associated with Adolescent Friendship Maintenance and Dissolution
\end{abstract}

Rebecca A. Owens

This study examined the association between early adolescents' friendship features and friendship outcomes (maintenance vs. dissolution and overall quality) following friendship problems. Also of interest was whether the reported causes of friendship problems and friendship dissolution differed. Early adolescents' (mean age $=12.45$ years; 118 girls, 82 boys) experiences with their friends were assessed through several written questionnaires. Six friendship features were used to predict friendship outcomes following problems: length of friendship, closeness, common experiences, balance of costs and rewards, personal characteristics, and expected ease of finding a new friend. Length of friendship and approval of a friend's personal characteristics predicted friendship dissolution. Personal characteristics and expected ease of finding a new friend predicted overall friendship quality. Predictors were similar for girls and boys. Also, friendship problems and friendship dissolution had different causes. Issues related to group membership or personal characteristics were reported as the causes of many friendship problems; friendship dissolution was most often caused by a lack of common experiences. The results illustrate that early adolescent friendship dissolution is similar to other relationship dissolution and that friendships do not necessarily end for the same reasons that problems occur between friends. 


\section{TABLE OF CONTENTS}

$\begin{array}{lc}\text { Abstract } & \text { ii } \\ \text { Introduction } & 17 \\ \text { Statement of the Problem } & 18 \\ \text { Hypotheses } & 20 \\ \text { Method } & 34 \\ \text { Results } & 42 \\ \text { Discussion } & 55 \\ \text { References } & 62 \\ \text { Appendix } & 81 \\ \text { Tables } & 95 \\ \text { Figure } & \end{array}$


Friendship Characteristics Associated with Adolescent Friendship

Maintenance and Dissolution

The purpose of the present study was to investigate the factors that are important to the maintenance and dissolution of early adolescent friendships. It is important to study early adolescent friendships because early adolescence is a time of many changes, including changes in friendships (e.g., Aboud \& Mendelson, 1996; Csikszentmihalyi \& Larson, 1984; Newcomb \& Bagwell, 1995; Rubin, Bukowski, \& Parker, 1998). Many investigations of friendship have been conducted, but most friendship research is centered on the formation and qualities of friendships. Additional research in the field should be focused on the factors associated with the continuation and dissolution of friendships. A common assumption among researchers is that friendships have positive effects on children and adolescents (Berndt \& Das, 1987; Claes, 1994; Lawhon, 1997; Mahoney \& Cairns, 1997). Assuming that friendships are desirable, it is valuable to understand what makes friendships last and what predicts their failure. Furthermore, most friendship research is based on investigators' assumptions about the factors that adolescents consider when they make new friends or choose to either maintain or end existing friendships. More research is needed to determine what is important from adolescents' perspectives. Information about what adolescents believe are the most important factors in determining friendship maintenance and dissolution would indicate whether friendship studies have been focused on issues that are important to adolescents. Individuals have an insider's perception of their friendships that differ from outsiders' perceptions (Furman, 1984; 1996; Ladd, Kochenderfer, \& Coleman, 1996). 
To understand the factors that are related to friendship maintenance and dissolution, it is necessary to consider a number of issues. Following is an overview of the literature that will be reviewed in this paper. First, friendship will be defined. Without a working definition of the construct, research on friendship has no focus. Second, information about friendships in early adolescence will be considered, because friendship maintenance may be especially important during this time in the life span. In particular, developmental changes in adolescent friendships and specific friendship factors (e.g., changing understanding of friendship; increased desire for intimacy) that are expected to be important to adolescents will be explored. Third, research on stability of friendships will be linked to the understudied area of friendship dissolution. Specific friendship features that have been found to be important to adolescents will be discussed. Links between friendship features and friendship maintenance and dissolution will also be suggested. Fourth, the importance of a focus on adolescents' perspectives on the maintenance or dissolution of their own friendships will also be discussed; such a perspective is an important addition to friendship research. Fifth, information about the dissolution of relationships in general will be considered and linked to friendship dissolution. Finally, potential predictors of friendship dissolution will be explored. Studying friendship dissolution predictors such as conflict may provide valuable insight about the break-up of friendships.

\section{Definition of Friendship}

Peers tend to spend time in environments where they are naturally together. For example, when adolescents go to school they often spend time interacting with peers, and within groups of peers, some members become friends. Friendships represent a special 
type of peer relationship. Auhagen (1996) explicates a general definition of friendship and explains that "friendship is a dyadic, personal, informal social relationship." In addition, there are several criteria which must be present if friendships are to be defined. Specifically, friendships are mutual relationships, are voluntary relationships, occur over time (i.e., they have past and future components), include positive emotions, include no overt sexuality, and have some value to the friends (Auhagen). In friendship relationships, the actions of one member of a pair depend on the actions of the other member (Wright \& Keple, 1981).

In addition to the basic components and criteria of friendships, several characteristics (also known as features or factors) are usually (although not always) present in friendships. For example, Auhagen's (1996) review of the literature suggests that friendships differ in terms of frequency, content, and quality of interactions, selfdisclosure, and closeness of the friendship. Furthermore, individuals enter friendships because they tend to enjoy each other's company; friends also share reciprocal affection (Rubin et al., 1998). Friends may also share private themes or rules that govern their interactions and define their relationships (Youniss, 1999). People who are friends generally share positive interactions, enjoy a common ground, work to resolve conflicts when they occur, tend to not dominate each other, have intimate discussions, and are faithful to each other (Newcomb \& Bagwell, 1995).

\section{Developmental Changes in Adolescent Friendships}

As children grow older, they begin to spend less of their free time with their parents and more time with their friends (Csikszentmihalyi \& Larson, 1984). Furthermore, from childhood to adolescence, individuals' expectations about friends 
change and the dynamics of friendships also change (e.g., Newcomb \& Bagwell, 1995;

Rubin et al., 1998; Selman \& Schultz, 1990). For example, Selman and Schultz suggest that adolescents experience a shift from friendships in which friends simply adapt to and cooperate with each other, to friendships based on mutual respect and support. That is, adolescents are able to see relationships from a new perspective. In particular, adolescents move from viewing friendships in terms of their own perspectives to viewing their friendships from the perspectives of their friends and others. Older adolescents are better able to accept the fact that their friends will have friends in addition to themselves than are younger adolescents. That is, younger adolescents may end friendships if their friends make new friends, but older adolescents are more likely to recognize that it is important for their friends to also have other relationships. Also, adolescents typically value intimate communication (i.e., sharing of information that is of a personal or private nature) (Kerns, Klepac, \& Cole, 1996) with their friends (Buhrmester, 1990). Thus, adolescents may identify intimate communication as an important factor to consider when maintaining or terminating existing friendships.

\section{Friendship Stability and Dissolution}

Investigations of friendship stability suggest that children and adolescents generally have stable friendships. For example, Berndt and Hoyle (1985) studied first, fourth, and eighth graders and found that most friendships were reciprocal and stable during a school year. Younger children gained more new friends than did older children. Older children seemed to maintain the friendships they had, but younger children were more likely to replace friends. In a similar investigation, fourth and eighth graders who did not demonstrate stable friendships displayed predictable patterns of answers in 
interviews about their friends (Berndt, Hawkins, \& Hoyle, 1986). Participants whose friendships ended during the school year reported that they had less intimacy and fewer interactions with their friends than did more stable friends, both at the beginning of the school year and at the end of the school year. Furthermore, high quality friendships in which reciprocity was practiced tended to be more stable across a school transition (Jiao, 1999).

It should be noted that although much of the research on friendship stability indicates that children and adolescents have stable friendships, the investigations have not addressed the question of why some friendships are stable and others are not (Bukowski, Newcomb, \& Hartup, 1996). A review of the friendship literature, however, suggests that adolescents seem to be more particular than children about the friendships they choose to keep (Aboud \& Mendelson, 1996). Perhaps there are particular factors associated with friendship stability whose absence predicts friendship dissolution. Together, the reports reviewed above suggest that stability may depend upon having numerous significant reciprocal interactions with friends. Thus, friendship dissolution may be related to having fewer important reciprocal interactions with friends. Additional information from the friendship quality literature will be reviewed to determine which friendship features also may be related to friendship dissolution.

\section{Important Adolescent Friendship Features}

Although most adolescents have at least some friends (Csikszentmihalyi \& Larson, 1984), not all friendships are the same. Friendships may differ, for example, in quality. As they become more particular about which friendships they would like to maintain (Aboud \& Mendelson, 1996), adolescents likely choose to maintain those 
friendships that they experience as positive. Positive friendship features have been identified using several methods, including the Friendship Quality Questionnaire (Parker \& Asher, 1993), the Friendship Qualities Scale (Bukowski, Hoza, \& Boivin, 1994), and the Network of Relationships Inventory (Furman \& Buhrmester, 1985). A variety of friendship features have been identified. Friendships that do not include such features may be more likely to dissolve. Some of the main factors related to friendship maintenance are outlined below. The potential relationships between these factors and friendship dissolution are also addressed.

Communication. Being able to communicate well with friends is important to adolescents. Friends are better able to resolve conflicts if they can communicate their objectives (e.g., Hartup, French, Laursen, Johnston \& Ogawa, 1993). Another aspect of communication that is particularly important to adolescent friendships is intimacy. Friendships with intimate communication offer many advantages to adolescents that friendships lacking intimacy do not offer. Intimacy is correlated with: social competence (e.g., Gavin \& Furman, 1996; Paterson, Pryor, \& Field, 1995); fewer feelings of general hostility (e.g., Buhrmester, 1990); higher self-esteem (e.g., Buhrmester; Field, Lang, Yando, \& Bendell, 1995); and low depression, more happiness, and better school adjustment (e.g., Field et al.). Furthermore, Hartup (1989) found that adults who had close, intimate friends in childhood had higher self-esteem and more intimate relationships than adults who were rejected as children.

The research outlined above suggests that communication, including intimate communication, in adolescent friendships is associated with a variety of positive outcomes; therefore, adolescents may benefit from good communication with friends. If 
communicating with friends is important to adolescents, adolescents whose friendships lack appropriate communication may be more likely to end friendships as compared to adolescents with more intimate friendships.

Support and Resources. Aboud and Mendelson (1996) suggest that high quality friendships are those in which each friend provides important social, emotional, and instrumental resources to the other friend. Fehr (1999) further suggests that stable friends typically provide support for each other. Specifically, friends may provide instrumental support (e.g., lending money) or emotional support (e.g., sticking up for a friend when rumors about the friend are spread). It is also important that the support and resources received from the relationship are not outweighed by the costs of being in the relationship (Rusbult, 1980). For example, individuals who spend a lot of time helping their friends solve problems expect that their friends will be willing to reciprocate. Therefore, adolescents are likely to maintain friendships from which they receive support and resources. Friendships in which at least one friend feels unsupported may be likely to dissolve.

Trust. Another important feature of adolescent friendships is trust (Azmitia, Lippman, \& Ittel, 1999; Claes, 1994; Selman \& Schultz, 1990). Specifically, adolescents typically want to know that their friends will not share secrets with others. Having trust in one's friends may be an important component of high quality friendships (Claes, 1994). In a comparison of adolescents who had been referred for psychiatric treatment and adolescents who had received no psychiatric treatment, Claes concluded that nonreferred older adolescents reported more trust in their friends as compared to referred adolescents. This suggests that high quality, trusting friendship relationships may be 
related to mental health and are therefore desirable. Early adolescents may terminate their friendships if they do not trust their friends (Azmitia et al., 1999).

Similar Identities and Interests. Researchers argue that friends tend to be like each other in many ways (Akers, Jones, \& Coyl, 1998; Newcomb \& Bagwell, 1995). For example, Newcomb and Bagwell suggest that friends share similar interests, activities, values, personalities, self-concepts, and levels of aggression. Akers et al. report that friends have similar attitudes about school-related activities and substance use. Friends are also typically similar in race and gender (Shrum, Cheek, \& Hunter, 1988 as cited in Hamm, 2000). Friends likely become more similar to each other over time (Berndt, 1999). That is, friends may influence each other such that each friend's attitudes and behaviors change to be more like the other's attitudes and behaviors.

Friendships are also affected by the identity development of the friends. During the adolescent years, individuals face the task of exploring what kind of person to become (Erikson, 1963). Erikson explains that during adolescence, individuals are faced with many new situations at the same time as they become increasingly concerned with what others think about them. As a result, adolescents try out a variety of possible social roles and decide which one fits the best.

Friendships during adolescence may be affected by the social roles individuals choose to explore. In a study of adolescent friends' identity development, Akers et al. (1998) found that friends demonstrated more similarities in identity development than did nonfriends. That is, friends had similar ideological identity characteristics, especially in levels of foreclosure (e.g., conforming to parents' ideas) and diffusion (e.g., lack of a clear focus) (Marcia, 1998). Friends were even more similar in interpersonal 
characteristics and in specific content areas such as dating. This suggests that adolescents are typically friends with people who have developed identities similar to their own identities. It is expected that adolescents will maintain friendships with individuals who have similar identities to their own and may dissolve friendships with others whose identities are different.

Common Experiences. Sharing common experiences may also enhance friendships (Devlin, 1996; Zarbatany, Hartmann, \& Rankin, 1990). In Devlin's report about an optional college orientation wilderness survival program, program participants indicated that they maintained their friendships with each other during their college years more than did non-participants. Therefore, common experiences may be associated with friendship stability. Adolescents who have been friends for a long time likely have shared many common experiences and, therefore, may be likely to maintain the friendship in the future. Fehr (1999) also suggests that friendships are often more stable when members of the relationship live close to each other. Living near friends presumably leads to the opportunity to share experiences. Thus, friendships probably continue partially because the friends share experiences. Without opportunities for common experiences, friendships may dissolve.

Zarbatany et al. (1990) found that sharing experiences with peers had multiple benefits for fifth and sixth graders. For example, preadolescents' peer activities provided a context for socialization, gave individuals a sense of belonging, and led to an enhanced concern for the self. Thus, participation in peer activities is likely desirable for preadolescents and adolescents. Those who engage in peer activities create common experiences among peers, which may aid in friendship maintenance. 
Commitment. Friends of many ages (Fehr, 1999), including adolescents (Azmitia et al., 1999), identify commitment as being crucial to friendship stability. According to Fehr, commitment to friends includes being reliable, respectful, honest, trustworthy, and helpful. Friendships are likely to continue when friends are committed to each other, and relationships seem likely to end when at least one friend is not committed to the friendship.

Personal Characteristics and Behaviors. A variety of personal characteristics are related to the desirability of particular adolescent friendships. For example, a study of children aged 8-15 who attended a summer camp indicated that variables such as social skills, behaviors, and reputations were important to the quality of friendship relationships (Parker \& Seal, 1996). In the investigation, a child perceived by others as having a good sense of humor, a willingness to playfully tease, and knowledge of gossip was likely to have more close friends than was a child who was shy and unwilling to be teased. Thus, friends who have attractive personal characteristics and who engage in behaviors that adolescents perceive as being positive may maintain friendships more successfully than do friends who lack such positive personal characteristics and behaviors.

Knowledge of Strategies. Knowledge of friendship formation strategies has been shown to be associated with friendship formation as well as friendship stability (Wentzel \& Erdley, 1993). That is, when sixth and seventh graders were asked to describe appropriate ways to make new friends, being able to generate a greater number of appropriate and inappropriate strategies was positively correlated with prosocial behavior and peer acceptance and was negatively related to antisocial behavior. According to Wentzel and Erdley, social behavior is a mediator between knowledge of strategies and 
peer acceptance. Thus, early adolescents who are able to identify a variety of problemsolving strategies and who engage in prosocial behavior are likely to be accepted by their peers. These adolescents may be able to generate several strategies for making friends and for solving friendship problems and may have more stable friendships.

Gender Differences. The friendship quality literature also suggests that adolescent males and females likely have friendships that differ in quality. For example, girls often experience more intimacy in their friendships (Field et al., 1995; Hartup, 1993; Raja, McGee, \& Stanton, 1992) and spend more time together as compared to boys (Hartup). Girls also provide more help, support, and guidance to their friends than do boys (Jones \& Costin, 1995; Parker \& Asher, 1993). Wheeler, Reis, and Nezlek (1983) and Zarbatany et al. (1990) found that girls tend to engage in conversations about personal issues, whereas boys tend to engage in activities of mutual interest and report fewer intimate conversations with their male friends. Gender differences in attraction to aggressive peers have also been found. That is, girls are especially attracted to aggressive boys (Bukowski, Sippola \& Newcomb, 2000). Because girls and boys value different friendship features, it is important to consider girls' and boys' friendship experiences separately as well as collectively. Girls and boys likely end friendships for different reasons because different friendship features are important to girls and boys (Bukowski et al.; Field et al.; Hartup; Jones \& Costin; Parker \& Asher; Raja et al.; Wheeler et al.; Zarbatany et al.). For example, girls' friendships may dissolve as a result of problems with communication or trust while boys' friendships may dissolve as a result of a lack of common interests. 
Summary. Research on friendship features suggests that high quality friendship relationships may be characterized by a number of factors, including: communication; support and resources; trust; similar identities and interests; common experiences; commitment; personal characteristics; and knowledge of friendship formation strategies. These characteristics may be important to the understanding of friendship stability. In general, friendships may be stable when friends communicate well and trust each other. Furthermore, friends who have similar interests and identities and who provide resources and support for each other may be likely to remain friends. Friendships are likely to be more stable when friends share common experiences, are committed to each other, and demonstrate positive personal characteristics and behaviors. Friendships that do not include such features may be of lower quality and may be more likely to dissolve. What is Important to Adolescents?

Researchers have identified a variety of characteristics of friendship relationships and have illustrated some of the implications of having high quality friendships. However, little information concerning which friendship features are most important to the maintenance or dissolution of adolescent friendships is available. Researchers can speculate about what is important to younger people, but information about important friendship factors needs to be gathered from the adolescents themselves. As Furman (1996) explains, adolescents are the best sources of information about what is important to them, because they have a different perspective on their own relationships than anyone else is able to have. In addition, individuals' perceptions of their friendships generally are indicative of relationship quality (Furman, 1984; Ladd et al., 1996). That is, friends generally give accurate accounts of the quality of their relationships. Adolescents are 
able to provide important information about their friendships because they seem to have a general understanding of friendships (Azmitia et al., 1999; Selman \& Schultz, 1990). Information about adolescents' perspectives on friendship would provide valuable insights into the concepts of adolescent friendship maintenance and dissolution.

\section{Dissolution of Relationships}

Few researchers have investigated the dissolution of adolescent friendships. In one investigation, Azmitia et al. (1999) found that adolescents reported that best friends were likely to break-up if they experienced conflict, untrustworthiness, exclusion, unhelpfulness, or diverging interests. Azmitia et al. also found that friendships may deteriorate if an individual's friend forms new friendships, has bad personal qualities, violates rules, or no longer lives near the adolescent. However, Azmitia et al. did not specifically address factors such as communication, identity development, support and resources, or knowledge of friendship strategies. These additional features are important to consider because other researchers have suggested that adolescents value the features in their friendships (e.g., Aboud \& Mendelson, 1996; Akers et al., 1998; Wentzel \& Erdley, 1993; Wheeler et al., 1983). Thus, without such friendship features, adolescents' friendships may dissolve.

Although few researchers have examined the dissolution of adolescent friendships, researchers have considered the dissolution of other types of relationships. For example, in an investigation of college students' romantic relationships, Simpson (1987) found that a variety of factors were related to relationship stability. Some significant factors included closeness of the relationship, duration of the relationship, and ease of finding a new partner (Simpson, 1987). That is, relationships were more likely to 
dissolve if the partners were less close to each other, had been in the relationship for a short time, and could be replaced easily. In a similar investigation, several predictors of the rate of romantic relationship termination were found. Romantic relationships were terminated more often if the partners were not perceived as being more desirable than alternative partners, spent little time together, were dissimilar in race, had little support from the partner's social network, and had been in the relationship for a short time (Felmlee, Sprecher, \& Bassin, 1990). In addition, Fehr (1999) suggests that going away to school, moving to a new area, developing a serious illness, marriage, and other factors may contribute to the dissolution of young adults' friendships.

Rusbult (1980) found support for additional factors that may be related to friendship break-ups. Rusbult provided evidence for the investment model of relationships, which suggests that satisfaction in friendship relationships is related to a good balance of costs and rewards within the friendship. Rusbult also expanded on the investment model to suggest that commitment to maintaining a friendship includes the assumption that one's friend is a better friend than would be alternative friends, and that the investments each friend has put into the friendship are relatively equal. Thus, friendships in which alternative friends are not desired and in which costs and rewards are balanced are likely to be maintained. Friendships with unbalanced costs and rewards or desired alternative partners are more likely to dissolve.

It is expected that early adolescent friendships may dissolve similarly to other relationships. That is, early adolescent friendships may dissolve if friends feel that they are able to find better friends, have been friends for a short time, do not get as much 
benefit out of the relationship as they put into it, or are not committed to maintenance of the friendship, for example.

\section{Conflict in Friendship}

Although many friendships end quietly (Sprecher \& Fehr, 1998), many do not. One specific potential threat to friendship stability involves conflict among friends. Conflict is best defined as behavioral opposition (Laursen \& Collins, 1994). Friends tend to have more conflicts than do nonfriends (Hartup et al., 1993). When they disagree, friends either resolve their conflicts or end the friendship. Laursen and Collins report that close adolescent friends typically strive for a compromise when they experience a conflict and that they usually maintain social interaction following a conflict, although the relationship may change. However, when conflicts are not resolved, friendships may end.

Rose and Asher (1999) suggest that conflict management is necessary for friendship maintenance. They report that children's goals and chosen strategies in response to a conflict situation are important in determining the effect of the conflict on the relationship. For example, in a mild conflict situation, striving for revenge tends to damage the friendship relationship. Also, antisocial actions tend to decrease acceptance by others. On the other hand, Rose and Asher found that children who tried to maintain relationships in conflict situations often had high quality friendships.

Differences in conflict resolution may also be found based on gender. Girls are more likely to explain their actions in conflict situations (Hartup et al., 1993) and are more likely to mitigate or diffuse the situation (Miller, Danaher, \& Forbes, 1986). Boys tend to use more heavy-handed tactics (Miller et al.). For example, a girl may avoid a 
fight by explaining her perspective or by leaving and acting as though the conflict did not bother her. She may attempt to solve the problem without hurting anyone's feelings. On the other hand, a boy may be more likely to argue for his point of view. He may focus on justice in the situation instead of on maintaining the friendship.

It is important to recognize that a specific negative event such as a fight is not necessary for a friendship to deteriorate. For example, a gradual change in interests may lead to friendship dissolution (e.g., Azmitia et al., 1999). Sprecher and Fehr (1998) suggest that friendships often dissolve passively; that is, there is no significant argument. Sprecher and Fehr further explain that friendship dissolution is very complicated and can be agreed upon by one or both members of the relationship. That is, because friendship includes a mutual agreement to be in the relationship, one friend's desire to end the relationship will lead to the dissolution of the friendship even if the other member of the relationship would like the friendship to continue.

\section{Summary}

The above review of the literature considered a number of issues. First, friendship was defined. Second, information about friendships in adolescence was considered, because friendship maintenance may be especially important during this time in the life span. Some of the developmental changes in adolescent friendships and specific friendship factors (e.g., a changing understanding of friendship, increased desire for intimacy) that were expected to be important to adolescents were explored. Third, research on stability of friendships as it is related to the understudied area of friendship dissolution was discussed. In this study, it was expected that features that are related to friendship stability also would be related to friendship dissolution. Specific friendship 
features that have been found to be important to adolescents were explored. Fourth, the importance of a focus on adolescents' perspectives of the maintenance or dissolution of their own friendships was discussed. The present study assessed friendships from early adolescents' perspectives. Fifth, because there has not been much research in the area of friendship dissolution, dissolution of other types of relationships was explored, and potential links between adolescent friendship dissolution and dissolution of other relationships were suggested. The present investigation addressed whether relationship dissolution was similar for different types of relationships. Finally, potential predictors (i.e., conflict; changing interests; nonmutual commitment) of friendship dissolution were explored. This investigation included further exploration of causes of friendship dissolution.

\section{Statement of the Problem}

Because of a lack of research attention to the dissolution of adolescent friendships, the findings of the current study contribute important information to the literature on friendship. In particular, the present study assessed the relationships among friendship features and friendship maintenance or dissolution. Specifically, would a lack of the features (e.g., long-lasting friendship; high levels of closeness; many common experiences; balance of costs and rewards; approval of a friend's personal characteristics; expectation that making new friends would be difficult) that have been found to be associated with friendship maintenance and high-quality friendships be associated with friendship termination or low-quality friendships after problems occur in friendships? Alternatively, would the features associated with friendship stability be unrelated to friendship dissolution? Furthermore, the present investigation sought to identify the most 
important reasons for friendship dissolution from adolescents' perspectives. This information can be used to confirm or challenge the assumptions about important adolescent friendship features in the existing literature. Because the benefits of having friends are commonly accepted, it is necessary to identify the factors of friendship maintenance and dissolution that are most important to adolescents. In addition, the present investigation examined the reasons early adolescents reported as precipitating friendship dissolution. This information adds to the current knowledge about friendship dissolution, which suggests that conflict plays a large role in adolescent friendship dissolution. More specifically, the present investigation provides information about comparisons of causes of friendship problems and causes of friendship dissolution to determine if friendships dissolve for reasons that are unrelated to friendship problems.

Hypotheses

The present investigation addressed three primary questions. First, the investigation assessed the relationship between adolescent friendship features and friendship maintenance or dissolution after a problem occurred. In other words, after problems occur between friends, are particular friendship features that were present before problems occurred associated with the quality of the friendship and its maintenance versus dissolution after problems occur? Based on information about romantic relationship dissolution (Felmlee et al., 1990; Rusbult, 1980; Simpson, 1987), it was expected that friendships that were shorter in duration before the problem, friendships in which the friends spent little time with each other before the problem occurred, and friendships whose members felt that their partners could be replaced easily would be of lower quality and would dissolve more often after problems as compared to 
friendships without such characteristics. It was also expected that friendships characterized by a lack of positive features such as a balance of rewards and costs, approval of the friend's personal characteristics, and closeness (e.g., Rusbult, 1980; Zarbatany et al., 1990), would be of lower quality and would dissolve more often as compared to friendships with more positive features. Furthermore, closeness (i.e., little intimacy or trust) before problems occurred was expected to be an important predictor of the quality of girls' friendships and whether girls' friendships ended following problems. Common experiences before problems occurred were expected to predict the quality of boys' friendships and whether their friendships ended after problems. Gender differences in predictors of friendship quality and dissolution of friendships following problems were predicted because girls generally place more importance on communication and trust, but boys generally value common experiences with friends (e.g., Hartup, 1993; Parker \& Asher, 1993; Zarbatany et al., 1990).

Second, the reasons adolescents reported for friendship dissolution were explored. The investigation included an examination of the issues adolescents identified when asked to explain the reasons for their actual friendship dissolution. It was expected that adolescents would provide reasons for friendship dissolution that were not exclusively related to conflicts and problems with friends. It was expected that adolescents would include a number of issues such as communication, ineffective conflict resolution strategies, lack of common experiences, or changing interests (e.g., Azmitia et al., 1999; Fehr, 1999; Felmlee et al., 1990; Rose \& Asher, 1999; Sprecher \& Fehr, 1998). Gender differences were also predicted for reasons for friendship dissolution. Specifically, girls were expected to end friendships as a result of problems involving communication and 
trust more often than were boys. On the other hand, boys were expected to end friendships more often as a result of problems relating to common experiences. Gender differences in friendship dissolution were expected because girls and boys value different features in their friendships (e.g., Hartup, 1993; Parker \& Asher, 1993; Zarbatany et al., 1990).

Third and finally, the association between causes of problems with friends and causes of friendship dissolution was explored. In other words, are the reasons adolescents give for friendship break-ups the same reasons they give for problems with friends? No specific associations were predicted; this research was exploratory.

Method

\section{Sample}

The participants were 200 sixth $(n=81 ; 49$ girls, 32 boys $)$, seventh $(n=83 ; 51$ girls, 32 boys), and eighth ( $n=36 ; 18$ girls, 18 boys) graders, a total of 118 girls and 82 boys. Parental consent and child assent were obtained before the participants took part in the investigation. The mean age of the participants was 12.45 years $(S D=.96$; range $=$ 10-15 years). Participants were early adolescents. Participants were considered early adolescents based on classifications in past research. For example, previous research has included studies of preadolescents who were generally younger than were the participants in the present investigation (e.g., Sroufe, Bennett, Englund, Urban, \& Shulman, 1993; Strough, Swenson, \& Cheng, 2001). Other research included participants whose average age (about 13 years) was similar to the average age of the participants in the present investigation (about 12.5 years); this research considered participants to be early adolescents (Buhrmester \& Furman, 1987). Bukowski et al. (2000) examined sixth- 
graders and referred to participants as early adolescents. This age group was selected because early adolescence represents a time of school and peer transitions. Thus, sixth, seventh, and eighth graders likely face choices about which friends to keep and which ones not to keep. As a result, the importance of various features of friendships may become particularly important during early adolescence, and friendship features may be related to friendship stability.

Demographic Characteristics

Demographic information was collected from participants' parents. Parents completed demographic questionnaires and were instructed to return them with their children's consent forms. Demographic information was not available for some of the participants, because some parents did not return the demographic questionnaire, returned blank forms, or indicated they did not want to disclose demographic information.

Most of the participants were white (72\%). In the sample, $4.5 \%$ of participants were of Asian or Pacific Islander decent, 1.5\% were African American, 1.5\% were Asian American and white, 1\% were Hispanic, 1\% were Hispanic and white, and 1\% were described as being from some other group. Information on race was unavailable for the remaining $17.5 \%$ of participants.

Regarding race, participants' parents were primarily white $(73 \%$ of mothers and $69 \%$ of fathers). An additional $4.5 \%$ of mothers and fathers were Asian Americans or Pacific Islanders. One percent of the mothers and fathers were African American, and $1.5 \%$ of mothers and $.5 \%$ of fathers were Hispanic. Also, $.5 \%$ of mothers and fathers were described as being from some other group. Racial information was not reported for $19.5 \%$ of mothers and $24.5 \%$ of fathers. 
Most participants' parents were married (70.5\%). For the sample, $8 \%$ of participants' parents reported that they were divorced or separated, and $4 \%$ indicated that they were single or widowed. An additional $17.5 \%$ of parents did not provide information about their marital status.

Participants' parents were generally well educated. Specifically, 33.5\% of mothers and $27.5 \%$ of fathers had a graduate degree. An additional $.5 \%$ of mothers and $1.5 \%$ of fathers had completed some graduate school. Twenty percent of mothers and $19.5 \%$ of fathers completed college, and $9.5 \%$ of mothers and $6.5 \%$ of fathers completed some college. An additional $15.5 \%$ of mothers and $16.5 \%$ of fathers completed high school only. Finally, $1 \%$ of mothers and $3 \%$ of fathers had not earned a high school diploma. Education information was not reported for $20 \%$ of mothers and $25.5 \%$ of fathers.

About half of the parents who provided occupation information indicated that they had white collar professions (e.g., professional or specialty), and about half had blue collar (e.g., transportation or factory) occupations. This distinction was based on the Occupational Classification System used by the U. S. Census (1987). Six percent of mothers indicated that they were housewives, $2 \%$ of mothers and $2.5 \%$ of fathers indicated that they were students, and $1 \%$ of mothers and $2 \%$ of fathers were disabled. Occupational information was missing for $19.5 \%$ of mothers and $20.5 \%$ of fathers.

\section{Procedure}

Participants were recruited from local middle schools, after-school programs, and sports teams in a small city in West Virginia. In addition, some potential participants were contacted through undergraduate students at West Virginia University. Parental 
consent and demographic information forms were distributed to students in several classrooms and after school programs. Parents were asked to consider granting permission for their children to take part in the investigation, and parents were also asked information about race, education, and occupation. Students who returned the forms with parental consent were asked to complete assent forms. After indicating their assent, participants completed the questionnaires. For participants who were recruited through sports teams or undergraduate students, parental consent forms, participant assent forms, and questionnaire materials were mailed to potential participants with postage paid return envelopes. Adolescents who agreed to participate returned all materials through the mail. Approximately 500 consent forms were distributed to schools and other organizations. It is estimated that about $40 \%$ of the early adolescents who received consent forms returned the forms. However, it this estimate is conservative. The exact return rate of the consent forms cannot be determined due to the distribution procedure. Teachers and other adults (e.g., guidance counselors; after-school program coordinators) distributed consent forms to potential participants, but the number of forms that were distributed is unknown. Furthermore, some participants received multiple copies of the consent form. Of the early adolescents who returned their forms, $87 \%$ had parental consent to participate in the study. All early adolescents who were present in school on the day that the study was completed gave assent to participate in the study. No participants dropped out of the study before completing the questionnaires.

Participants responded to a written questionnaire. Most (85\%) participants completed the materials in their classrooms at school or during after school programs; the remaining $15 \%$ of participants completed questionnaires somewhere other than at school. 
Teachers read instructions (See Appendix A) to the students, and students completed the materials individually. Teachers were asked to monitor students so that participants did not discuss their answers with classmates. Each participant received a folder with all of the materials for the investigation and placed the materials back into the folder upon completion so that privacy was evident. Participants who were recruited through sports teams and undergraduates were given the same information about the study that participants were given at school; participants from teams and undergraduate contacts read the instructions. Then, participants were asked to complete the questionnaires somewhere in private.

The names of individuals who returned their consent forms were entered into a drawing to win several prizes. Some participants won movie tickets, and some won gift certificates to the mall. Other participants did not receive reimbursement for taking part in the study. Undergraduate students who provided names of potential participants were given extra credit points in psychology courses for their help with the study.

\section{Materials}

Demographic Information. Participants indicated whether they were male or female, their grade in school, race, and birth date. This information was used to generate gender comparison groups and descriptive information about the participants. Also, participants listed the first names of all of their friends and indicated whether each friend was a male or a female. Information about participants' friends was used as background information and will be used for future investigations. See Appendix B for the demographics measure. 
Friendship Problems Questionnaire. After completing the demographics information, participants responded to questions about problems they have had with their friends on the Friendship Problems Questionnaire (see Appendix C). The Friendship Problems Questionnaire was adapted from a measure of everyday problem solving (Sansone \& Berg, 1993). Each participant recalled a problem or conflict with a friend that occurred within the past year. Participants explained what happened in the problem and what the main cause of problem was. Participants wrote their answers and were asked to provide as many details as possible. Participants also indicated how long ago the problem occurred and rated the importance of the problem. After describing the problem, participants responded to questions about their relationships with the friends with whom they had the identified problems. Overall friendship quality following the problem was based on the question, "How good of friends were you after the problem?" (question $48 ; 1=$ not friends $; 2=$ OK friends $; 3=$ in the middle $; 4=$ pretty good friends; $5=$ best friends). Friendship outcome (friendship maintained or dissolved) was based on the answer to the yes-or-no question asking, "Are you still friends with the person?" (question 9).

Participants also answered a variety of other questions about the problem (e.g., goals for solving the problem, actions taken to prevent problems, whether or not the problem was surprising, who was at fault for the problem, friendship features after the problem). This information was collected for use in future research by the principal investigator.

Friendship Endings Questionnaire. Next, participants were asked to think about someone who used to be a friend, but was no longer a friend. Participants provided 
information about a friendship that ended by responding to items on the Friendship Endings Questionnaire (See Appendix D). They explained the events surrounding the break-up of the friendship. Participants explained what happened when the friendship ended and what the main cause of the friendship ending was. Participants wrote their answers and were asked to provide as many details as possible. Participants also rated the importance of keeping the friendship $(1=$ not at all; $2=$ a little bit; $3=$ in the middle; $4=$ pretty important $; 5=$ very important $)$.

Participants also answered questions about friendships that will be used for future research by the principal investigator. Specifically, participants indicated what their goals were in the situation, what (if anything) was done to try to avoid the dissolution, and the likelihood that the friendship will resume in the future. Participants rated the extent to which the ending of the friendship was their own fault, their friend's fault, or neither person's fault. Participants also rated the status and several features of the friendship before and after the break-up.

\section{Data Reduction}

Coding Categories. Open-ended responses to the questions, "What was the main cause of the problem?" and "What was the main cause of the friendship ending?" were coded. Friendship problems were placed into one of 12 mutually exclusive and exhaustive categories that corresponded to the friendship features thought to be important to adolescents. Specifically, causes that adolescents identified in response to the question "What was the main cause of problem?" were coded as problems with intimacy, support and resources, trust, similar identities or interests, common experiences, commitment, personal characteristics and behaviors, knowledge of friendship strategies, other, none, 
blank, or unsure. For example, a statement such as, "My friend and I didn't talk about our feelings" was coded as an intimacy problem. "My friend would not stick up for me" was categorized as a problem with support and resources. An example of a trust problem was, "She told our whole lunch table a secret about me." A statement such as, "He likes to do things with the popular crowd now and I don't" was a problem with similar interests. Common experience problems included statements such as, "We don't play on the same team anymore." Problems with commitment would have included statements such as, "She doesn't do anything to make our friendship last." Problems about specific characteristics of friends such as "He is just really rude" were coded as personal characteristics or behavior problems. Responses such as, "He really isn’t good at being friends" were coded as problems with friendship strategies. Problems were coded as other if participants described problems but did not give enough information to code the problem (e.g., "He did not wake up.") or if the problem was not directly related to the friendship (e.g., "She and her mom had a bad day."). Participants' responses were coded as none if participants indicated that they had never experienced a problem with a friend. A code of blank was assigned if participants did not respond to the question. If participants indicated that they were not sure what caused the problem, their responses were coded as unsure. The other category was examined to see if responses fell into an identifiable category. Because several participants indicated that they had problems related to misunderstandings, the category of misunderstanding was added. Statements such as, "We misunderstood each other" were included in the new category.

Because some of the reasons for problems with friends had low frequencies, some categories were combined for the analyses. First, intimacy was the reported cause of only 
3 participants' problems and was, therefore, combined with misunderstanding; the resulting category was labeled communication. Problems with intimacy and problems with misunderstanding are both related to communication issues. Second, commitment (which was a problem for only 2 participants) and similar interests were combined to form the new category of group membership. Many of the problems with similar interests were related to popularity and exclusion of individuals from a given group of peers. Similarly, lack of commitment included friends no longer wishing to include participants in their circles of friends. Thus, the category of group membership was appropriate. Finally, no participants identified problems due to friendship strategies. Thus, the category was not used for the analyses. Furthermore, codes of unsure and other were combined for the analyses; either response indicated that a problem was present but that the problem could not be attributed to any of the other problem categories. Four participants (2\%) indicated that they had not experienced a problem with a friend or did not identify a main cause of the problem, and those participants were not included in the analyses.

The same coding scheme was used for categorizing causes of friendship endings. Coding of friendship endings involved categorizing responses to the question "What was the main reason the friendship ended?" into one of the 12 mutually exclusive and exhaustive categories described above (i.e., intimacy; support and resources; trust; similar interests or identities; common experiences; commitment; personal characteristics or behaviors; friendship strategies; other; none; blank; unsure). Because some of the reasons for friendship endings had low frequencies, some categories were combined for the analyses. The combined categories were the same as were the combined categories for 
problems with friends. Intimacy was the reported cause of only 2 participants' dissolved friendships and was, therefore, combined with misunderstanding; the resulting category is communication. Commitment was the cause of 4 friendship endings and was combined with similar interests to form the new category of group membership. No participants identified friendship termination due to friendship strategies. Thus, the category was not used for the analyses. Furthermore, codes of unsure and other were combined for the analyses; either response indicated that a friendship had ended but that the reason for the termination could not be attributed to any of the other ending categories. Only 3 ended friendships fell into this combined category. Twenty-eight (14\%) participants either left the question blank or indicated that they had never experienced friendship dissolution, so their information was not included in the analyses.

Coding Procedure. Two individuals, the author and an undergraduate research assistant, completed the coding. To code responses, the coders read the descriptions of the problems and situations surrounding friendship dissolution. Coders also read the reported main cause of the problem and the main cause of the friendship ending. Approximately $15 \%$ of the data were used to train coders to use the coding scheme. The coders met weekly to discuss the codes until reliability was achieved. When coders' opinions of the classifications differed, the principal investigator's codes were used. After reliability was achieved, the coders divided the remaining data; each coded half of the remaining participants' descriptions.

The overall Kappa coefficient for $40 \%$ of the data for main causes of problems was .78. For intimacy problems, the Kappa coefficient was .49, and for problems with support and resources, the Kappa coefficient was .63. Kappa coefficients for problems 
with trust, similar interests, and common experiences were $.89, .81$, and 1.00, respectively. The Kappa coefficient for problems with personal characteristics was .75 . Kappa coefficients were not obtained for problems with commitment or problems with friendship strategies, because those categories were not used. The Kappa coefficient for other was .75, and the Kappa value for unsure was .85. The Kappa coefficient for problems with misunderstanding was .82 .

For main reasons for friendships ending, reliability of the coding was also established between two coders (the author of the study and an undergraduate research assistant). The Kappa coefficient for $40 \%$ of the data for main causes of friendship endings was .95. Kappa coefficients for intimacy and support and resources were 1.00 and .86 , respectively. The trust category had a Kappa coefficient of 1.00 , and the value for similar interests or identities was .89. The Kappa coefficient for common experiences was $.97 ; 1.00$ was the value for commitment. The personal characteristics category had a Kappa coefficient of .92. The Kappa coefficients for friendship strategies and other could not be computed because no codes were given for those categories. Kappa values for none and blank were both 1.00. No cases of unsure were coded. The Kappa coefficient for misunderstanding was .66.

Friendship Feature Scales. Features of participants' friendships were assessed based on information from the Friendship Problems questionnaire. Friendship features were assessed via responses to questions about 12 friendship features. Features included intimacy, support and resources, trust, similar interests, common experiences, commitment, personal characteristics, knowledge of friendship strategies, length of friendship, amount of time spent with friend, closeness of the friendship, and expected 
ease of finding a new friend. Participants rated the above friendship features for specific friendships both before and after the problems happened. Ratings of friendship features before the problem were used as predictors of friendship outcomes after problems. Ratings of friendship features after the problems will be used for future research. Answering questions about friendship features before and after problems encouraged participants to think carefully about the difference or similarity in friendship features before and after problems.

Because it was expected that some of the above twelve features would be closely related to each other, some of the features were combined to form a total of six independent variables, which were then used to predict friendship dissolution, maintenance, and overall friendship quality. Each participant received a score for each of the seven friendship features. See Tables 1 for descriptive statistics for the friendship features. When responses to more than one question were used to assess a particular friendship feature, responses to all questions were combined to obtain a score. First, length of friendship was assessed by one question (question 19), which asked how long the participant had been friends with the person they described (less than 1 year through more than 10 years). Reported friendship lengths ranged from less than one year to more than 10 years, indicating that the full range of possible responses was utilized $(M=3.68$, $S D=2.99)$.

Second, closeness included questions about intimacy, trust, commitment, and support and resources. Intimacy questions included questions 20 and 22, which asked how often participants and their friends told each other how they were feeling and what they were thinking $(1=$ not at all; $5=$ all the time $)$. Trust was measured by asking how 
much participants trusted their friends before the problems occurred (question $24 ; 1=$ not at all; 5 = very much). Question 26 was a measure of commitment and asked how much participants and their friends tried to make their friendships as good as they could be before problems occurred $(1=$ not at all; $5=$ very much $)$. Support and resources were measured with question 28, which asked how much participants and their friends helped each other before problems occurred $(1=$ not at all; $5=$ very much $)$. The average of the 5 questions was computed to determine the closeness score. Scores ranged from 1 to 5, indicating that the full range of possible scores was used $(M=3.31, S D=1.00)$. Higher scores indicated closer friendships. Internal validity for the scale was high; Cronbach's alpha for the closeness scale was .84 .

Third, common experiences were assessed by computing the average of responses to questions about similar interests and common experiences. Similar interests were assessed by question 30, which asked how much participants and their friends liked to do things together before problems occurred $(1=$ not at all; $5=$ very much $)$. Common experiences were measured with question 32, which asked how often the friends did things together before problems occurred $(1=$ never; 5 =almost always $)$. Higher scores indicated that the friends reported more common experiences. Internal validity was high for the scale $(\alpha=.75)$. Time spent together was originally a separate independent variable, however because time spent together was highly correlated with common experiences $(r=.73, p<.01)$, question 44 (amount of time spent together; $1=$ none at all; $5=$ very much) was added into the common experiences scale. This increased the reliability of the common experiences scale $(\alpha=.85)$. Thus, the common experiences 
scale includes questions 30,32, and 44. The scores for common experiences ranged from 1 to 5 ; the entire range of potential responses was utilized $(M=3.72, S D=1.07)$.

Fourth, balance of rewards and costs was the difference between responses to questions 34, which asked how much participants put into their friendships before problems occurred, and question 38 which asked how much participants got out of their friendships before problems occurred $(1=$ nothing at all; $5=$ very much $)$. Scores for balance of costs and rewards were computed by subtracting responses to question 38 from responses to question 34. Thus, this score assessed the balance of the effort the participant put into maintaining the friendship and the benefit the participant received from the friendship. Friendships in which the person felt as though he or she put more effort into the friendship than he or she got out of the friendship were considered to be costly. Higher scores indicated that participants put more effort into the friendship than they benefited from the friendship (i.e., the friendship was costly). Scores ranged from -4 to $3(M=-.18, S D=1.03)$. The entire possible range of scores was -4 to 4 .

Fifth, information about personal characteristics was obtained from question 42, which asked how much participants liked the kinds of people their friends were before problems occurred $(1=$ not at all; $5=$ very $m u c h)$. Responses ranged from 1 to $5(M=$ $3.87, S D=1.08)$

The sixth feature was expected ease of finding a new friend and was assessed with question 46. This question asked how easy it would be for participants to find new friends if the friendships they described were to end $(1=$ impossible; $5=$ extremely easy). Responses to the ease of finding a new friend scale ranged from 1 to 5; the entire range of 
scores was used $(M=3.85, S D=1.11)$. Correlations among the friendship features and friendship outcomes are found in Table 2.

Results

Prior to conducting analyses that addressed the primary research questions, characteristics of the problems participants reported were examined. Next, to answer the research questions, three sets of analyses were conducted. The first question was whether friendship features before problems predicted whether friendships were maintained or dissolved and the quality of the friendship after the problem. This question was addressed with a logistic regression analysis predicting friendship dissolution or maintenance from friendship features and with a multiple regression analysis predicting overall friendship quality from friendship features. The second aim of the investigation was to identify reasons early adolescents identified for causes of friendship endings. Descriptive statistics were computed to determine the frequencies of different causes of problems in friendships and causes of friendship dissolution. Third, the association between causes of friendship problems and causes of friendship dissolution was examined. A series of chi-square analyses was conducted to determine the relationship between reported causes of problems with friends and reported causes of friendship dissolution.

\section{General Information}

Based on participants' responses to items on the Friendship Problems Questionnaire, early adolescents reported information about problems that were of medium importance. Specifically, the mean rating of importance of the problem was $3.16(S D=1.30 ; 1=$ not at all important, $2=$ a little bit important, $3=$ in the middle, $4=$ 
pretty important, $5=$ very important). The mean response to the question, "How important was it to you to keep this friendship?" was $3.69(S D=1.32 ; 1=$ not at all important, $2=$ a little bit important, $3=$ in the middle, $4=$ pretty important, $5=$ very important), indicating that early adolescents thought it was moderately important to keep the reported friendship when problems occurred. Responses for the importance of the problems and for the importance of keeping the friend ranged from 1 to 5 ; the entire possible range was used.

Early adolescents indicated how long ago the problems occurred $(1=$ less than 1 week, $2=$ about one week, $3=2-4$ weeks, $4=1$ or 2 months, $5=3$ or 4 months, $6=5$ or 6 months, $7=7$ or 8 months, $8=9$ or 10 months, $9=11$ or 12 months). The mean response for how long ago problems occurred was $4.87(S D=2.50)$. Responses ranged from 1-9.

Participants had been friends with the people with whom they described for an average of 3.68 years $(S D=2.99)$. Reported lengths of friendships ranged from less than one year to over 10 years.

For the Friendship Endings Questionnaire, early adolescents rated the importance of keeping their friendships as $2.84(S D=1.44)$ on a scale of 1 (not at all important) to 5 (very important). Scores ranged from 1 to 5 . On average, early adolescents reported that their friendships ended 7-9 months before they completed the questionnaires. Responses were classified as $1=$ less than 1 week, $2=$ about 1 week, $3=2-4$ weeks, $4=1-3$ months, $5=4-6$ months, $6=7-9$ months, $7=10-12$ months, $8=$ more than 1 year $(M=6.26, S D=$ 2.12). The range of scores was 1 to 8 . 
The average length of participants' friendships before the friendships ended was 3.42 years $(S D=2.67)$. Reported lengths of friendships ranged from less than one year to over 10 years.

\section{Friendship Maintenance or Dissolution After Problem Occurrence}

The first purpose of the investigation was to determine whether friendship features before problems occurred predicted whether friendships would be maintained or would dissolve after problems occurred. A logistic regression analysis was conducted to determine whether or not each of six friendship features was related to a dichotomous friendship outcome after a problem occurred (See Table 3). Friendship outcome was assessed by the yes-or-no question, "Are you still friends with the person?" The six predictors included: length of the friendship; closeness; common experiences; a balance of rewards and costs; personal characteristics; and expected ease of finding a new friend. The equation using the six predictors was significant $\left(\chi^{2}(6, N=183)=38.22, p<.001\right)$ and correctly classified $83.6 \%$ of the respondents ( $94.5 \%$ of maintained friendships; $40.5 \%$ of dissolved friendships). The Nagelkerke $\mathrm{R}^{2}$ value was .297 , indicating that the set of predictors accounted for $29.7 \%$ of the variance in friendship dissolution. This finding indicates that, as a set, the predictors reliably distinguish between friendships that end and friendships that do not end following friendship problems. According to Wald criterion, length of friendship and personal characteristics reliably predicted whether or not friendships ended $(z=4.08, p<.05$ and $z=12.08, p<.001$, respectively). Ease of finding a new friend was a marginally significant predictor of friendship dissolution $(z=$ $3.26, p=.07)$. 
The odds ratios (O.R.) indicated that the predictors differed in predictive utility (See Table 3). Specifically, each year that early adolescents had been friends with the person they described was associated with a $15.6 \%$ decrease in the likelihood of friendship dissolution. Also, each incremental increase (1 to 5) of approval of friends' personal characteristics was associated with a $60.7 \%$ decrease in the likelihood of friendship dissolution. Finally, increasing one increment in expected ease of making new friends was associated with a $51.1 \%$ increase in the likelihood of friendship dissolution.

The logistic regression analysis was also conducted separately for girls and boys to allow for a gender comparison (See Tables 2 and 3). For girls, the equation using the six predictors was significant $\left(\chi^{2}(6, N=108)=23.53, p=.001\right)$ and correctly classified $88.9 \%$ of the respondents $(97.8 \%$ of maintained friendships; $44.4 \%$ of dissolved friendships). The Nagelkerke $\mathrm{R}^{2}$ value was .330 ; the predictors accounted for $33 \%$ of the variance in friendship endings. Thus, for girls, the set of predictors reliably distinguished between friendships that ended and friendships that did not end following friendship problems. According to Wald criterion, length of friendship $(z=6.38, p=.012)$ and personal characteristics $(z=5.61, p=.018)$ reliably predicted friendship status for girls. The odds ratios differed in predictive utility (See Table 4). For each year that girls were friends, there was a $30.4 \%$ decrease in the odds of reported friendship dissolution following problems. In addition, girls who reported that they approved of their friends' characteristics before problems occurred were less likely to indicate that their friendships ended following problems with friends than were girls who reported that they did not like the kind of people their friends were before problems occurred. Specifically, each 
incremental increase ( 1 to 5 ) of approval of friends' personal characteristics was associated with a $63.1 \%$ decrease in the likelihood of friendship dissolution.

For boys, the equation using the six predictors was significant $\left(\chi^{2}(6, N=75)=\right.$ $19.81, p=.003)$ and correctly classified $81.3 \%$ of the respondents $(94.6 \%$ of maintained friendships; $42.1 \%$ of terminated friendships). The Nagelkerke $\mathrm{R}^{2}$ value was .343 , indicating that $34.3 \%$ of the variance in friendship ending was accounted for by the set of predictors. Thus, the set of predictors reliably predicted whether friendships would continue or end after problems occurred in the friendships. According to Wald criterion, only personal characteristics reliably predicted friendship status $(z=6.94, p=.008)$ (See Table 5). For each one unit increase in the approval of friends' personal qualities, boys were $65 \%$ less likely to report friendship dissolution.

\section{Friendship Quality After Problem Occurrence}

Multiple regression analyses were conducted to predict the overall quality of the friendship following a problem. Overall friendship quality was assessed by the question, "How good of friends are you and your friend?" The same six variables described above were used to predict overall friendship quality. This analysis was also performed separately for girls and boys.

In the equation that included information from both girls and boys, the set of predictors predicted a significant amount of the variance in the quality of friendships following problems with friends $(F(6,177)=14.01, p<.001)($ See Table 6$)$. The adjusted $R^{2}$ value for the multiple regression including both girls and boys was .299. Two factors were significant individual predictors of friendship quality. Personal characteristics $(\beta=.34, p<.001)$ and expected ease of finding a new friend $(\beta=-.23, p<$ 
.001) each accounted for a significant portion of the variance in friendship quality. That is, participants who reported greater liking of the kind of person their friend was before the problem occurred reported higher quality friendships following problems. Participants who reported that it would be more difficult to find new friends if their friendships ended reported higher quality friendships following friendship problems.

Multiple regression analyses were computed separately for girls and boys (See Table 6). For girls, the adjusted $R^{2}$ value was $.259(F(6,102)=7.295, p<.001)$. Girls who reported that they were closer to their friends before the problems occurred reported higher quality friendships after problems $(\beta=.26, p=.046)$. Expected ease of finding a new friend was also a significant predictor of friendship quality $(\beta=-.25, p=.004)$. Girls who reported that they expected it to be more difficult to make new friends were likely to report higher quality friendships following problems with friends.

Results of the multiple regression analysis for boys indicated that the set of predictors accounted for approximately $38 \%$ of the variance in friendship quality $(F(6$, $68)=8.66, p<.001)$. Personal characteristics and expected ease of finding a new friend were individual significant predictors of friendship quality $(\beta=.456, p<.001$ and $\beta=$ $.232, p=.014$, respectively). That is, boys who reported greater liking of their friends' personal characteristics before the problem reported higher quality friendships following problems. Boys who reported that they expected it to be easier to make new friends reported lower quality friendships following friendship problems.

\section{Summary}

Results of the logistic and multiple regression analyses indicated that liking of a friend's personal characteristics prior to the friendship problems predicted whether 
friendships would end or continue, as well as the overall quality of the friendship following problems. Specifically, greater liking of friends' personal characteristics was associated with friendship maintenance following problems for both girls and boys. Early adolescents who indicated greater liking of their friends' personal characteristics also reported higher quality friendships following problems. Length of friendship was an additional significant predictor of whether or not friendships would continue following problems. That is, early adolescents who reported friendships that were longer in duration prior to problems were less likely to report that their friendships ended following problems. Early adolescents who indicated that they thought it would be difficult to make new friends reported higher quality friendships following problems. However, expected ease of finding new friends was only a marginally significant predictor of whether or not friendships would dissolve following friendship problems.

Some gender differences in predictors of friendship maintenance or dissolution were also found. First, length of the friendship predicted whether or not girls' friendships ended following problems but did not predict whether or not boys' friendships ended following problems. In addition, closeness of friends prior to problems predicted the overall quality of girls' friendships, but not boys' friendships, following problems.

\section{Causes of Friendship Dissolution}

Another aim of the study was to investigate the reasons early adolescents gave for ending their friendships. Friendships were most likely to end because of issues related to common experiences (34.7\%) (See Figure 1). Issues related to group membership accounted for $22.4 \%$ of reported friendship endings, and issues related to personal characteristics accounted for $20.0 \%$ of terminated friendships. Trust issues were the 
reported causes of $11.8 \%$ of terminated friendships, and support and resources and communication accounted for $6.5 \%$ and $2.9 \%$ of ended friendships, respectively. Other causes of friendship endings were reported by $1.8 \%$ of participants.

\section{Causes of Friendship Problems}

For friendship problems, results indicated that $21.2 \%$ of participants reported problems with group membership, and $20.6 \%$ reported problems with personal characteristics. Problems with trust accounted for $17.1 \%$ of the problems. Communication problems and problems with support and resources were each reported by $13.5 \%$ of the respondents. Other problems were reported $12.9 \%$ of the time, and problems with common experiences were reported by $1.2 \%$ of respondents.

\section{Friendship Problems and Dissolution}

The third aim of the investigation was to determine if early adolescents' reported causes of problems with friends were the same as their reported causes of friendship dissolution. A series of chi-square tests was used to assess this relationship. First, a 7 x 7 chi-square test was used to determine the prevalence of the 7 causes of problems with friends and friendship endings (communication, support and resources, trust, group membership, common experiences, personal characteristics, and other or unsure). Test statistics could not be computed for the $7 \times 7$ chi-square test due to a large number of empty cells. However, descriptive information was obtained from the analysis. Next, a 2 x 2 chi-square analysis was conducted for each of the seven causes to determine if there was a significant difference in the causes of friendship problems and friendship endings. Test statistics were not reliable, however, because the cell counts were not high enough. One assumption of the one-way chi-square is that if there are two categories (i.e., 
problem and ending), then cell counts need to be at least 10 (Heiman, 1992); all of the $2 \mathrm{x}$ 2 chi-squares included at least one cell with a count of less than 10.

Chi-square analyses also were computed to compare the prevalence of each type of problem with friends and each reason for friendship termination between boys and girls (See Table 7). Each analysis was a 2 (gender: male; female) x 2 (category of problem or ending: present; absent) comparison. For problems with friends, gender differences were significant for trust $\left(\chi^{2}(1, N=196)=3.960, p=.047\right)$. Of the participants who identified trust as the main cause of their friendship problem, $75 \%$ were girls and $25 \%$ were boys. There were no significant gender differences for any of the other categories of friendship problems (i.e., communication, support and resources, group membership, common experiences, personal characteristics, and other or unsure). For main causes of friendship endings, there were no significant gender differences.

\section{Discussion}

The main goal of the study was to identify the relationship between various friendship features and friendship maintenance, dissolution, and friendship quality following friendship problems. In other words, when problems occur between friends, are particular friendship features associated with maintenance versus dissolution of the friendship? For friendships that are maintained, are friendship features related to the overall quality of the friendship following problems? Also of interest was the question of whether or not adolescents end friendships for the same reasons that they experience problems with their friends. That is, are the reasons adolescents give for friendship break-ups the same reasons they give for problems with friends? The findings suggest that some features of friendships, including length of the friendship, expected ease of 
finding a new friend, approval of a friend's personal characteristics, and closeness do predict friendship maintenance or dissolution and overall friendship quality. Overall, similar features appeared to be important to both girls and boys. Furthermore, findings suggest that early adolescents do not end friendships for the same reasons that they report having problems with friends. For example, common experiences were identified often as causes of friendship dissolution but rarely as causes of friendship problems. Together, the results suggest that early adolescents' friendships end for the same reasons that other types of relationships (e.g., romantic relationships) end. Furthermore, findings suggest that it is important to consider that friendships are likely to dissolve for reasons other than because of conflicts with friends.

\section{Friendship Maintenance or Dissolution Following Problems}

Results indicated that length of friendship before the problem predicted whether or not friendships ended. Friendships that were of longer duration were likely to continue following friendship problems, whereas newer friendships were likely to end following problems. This finding was expected based on past research. Previous research suggested that shorter romantic relationships were more likely to end than were longerlasting relationships (Felmlee et al., 1990). Thus, findings of the present investigation in combination with findings of previous research suggest that both friendships and romantic relationships may dissolve for some of the same reasons.

There was some indication that early adolescents who expected it would be easy to make new friends were more likely to experience friendship dissolution following problems with friends. This finding also is consistent with research on romantic relationships. For example, Simpson (1987) reported that people who thought it would 
be easy to find new romantic partners were more likely to terminate relationships than were those who felt it would be difficult to form new relationships. Perhaps individuals who think that they can form new relationships believe that keeping a specific friend is not necessary if there are problems with the friend. Early adolescents who think that they can make new friends may avoid putting effort into reconciling with a friend following a problem; instead, new friendships could be formed.

Friends who reported that they approved of their friends' personal characteristics were likely to experience friendship maintenance following problems, and friends who reported that they did not approve of their friends' personal characteristics were likely to experience friendship dissolution. This finding is consistent with previous research on adolescent friendships. Azmitia et al. (1999) found that adolescents who reported that they disliked friends' personal characteristics were likely to experience friendship termination. Thus, in addition to features of friendships, individual friends' personal characteristics are related to friendship outcomes.

Closeness of friendships was not predictive of friendship termination or maintenance. Contrary to expectations, friendships that were less close were not more likely to terminate following problems. This surprising finding could have been due to differences between this study and previous research. For example, Simpson (1987) focused on the closeness of romantic relationships and found that closeness was a predictor of dissolution. Perhaps closeness has a different meaning in the context of friendship relationships and romantic relationships. That is, friendships do not include a sexual component (Auhagen, 1996), but romantic relationships may include a sexual component. Furthermore, early adolescents' friends are primarily same-sex friends, but 
romantic relationships typically are cross-gender relationships. It is possible that closeness means something different in the context of sexual or cross-gender relationships than it does in nonsexual or same-gender relationships.

Also unexpected was the finding that a lack of balance between rewards and costs was not predictive of friendship maintenance or dissolution. Rusbult (1980) found that friendships were likely to end when friends felt that they put too much effort into the friendship compared to the benefits they received from the friendship. That is, friendships were likely to end if friends felt that the costs of being in the relationship outweighed the benefits of being in the relationship. However, Rusbult's sample was an adult sample. Thus, early adolescents may not have evaluated the costliness of their friendships, or they may not be bothered by unequal effort in friendships. In addition, the present study included only two questions about costs and rewards. Perhaps the balance of costs and rewards would have been a predictor if more information about costs and rewards had been obtained.

It was expected that lack of common experiences prior to friendship problems would predict friendship dissolution following problems; however this was not found. Previous research suggested that friendships were likely to be maintained when friends shared experiences (e.g., Devlin, 1996; Zarbatany et al., 1990). Similarly, Berndt et al. (1986) found that experiencing few interactions with friends was related to friendship dissolution. Perhaps common experiences were not predictive of friendship outcome due to the nature of the common experiences the adolescents in the study reported. Specifically, participants who shared common experiences with their friends may not have been able to choose whether or not they would share experiences with particular 
friends. For example, friends may have been in the same classes at school, on the same sports teams, or have lived in the same neighborhood. It is likely that such sources of common experiences did not encourage friends to be interested in maintaining friendships. If respondents had reported about only common experiences that they had chosen to have with friends (e.g., going to the movies together), it is possible that sharing common experiences would have predicted friendship outcome.

\section{Friendship Quality Following Problems}

Similar to the findings regarding whether friendships were maintained or dissolved following problems, liking a friend's personal characteristics before the problem was predictive of high quality friendships following friendship problems. This finding is consistent with previous research. For example, Parker and Seal (1996) found that social skills and behaviors were related to friendship quality. Specifically, children whose personal characteristics (e.g., good sense of humor; willingness to playfully tease) were most liked by other children had higher quality friendships as compared to children with less desirable characteristics. It is likely that adolescents who like their friends' personal characteristics are able to overlook some problems with friends or put effort into resolving the problems. If this is the case, then friendships would continue to be high in quality even after problems occur.

Early adolescents who reported that they felt it would be easy to make new friends reported lower quality friendships following problems. This finding was similar to the findings for friendship maintenance or dissolution. Perhaps early adolescents who believe that they could easily replace their friends are not interested in resolving friendship problems, because it would be easier replace the friend than to put effort into 
recovering the quality of the relationship. Perhaps adolescents who believe that they can make new friends easily do not resolve their problems; this lack of problem resolution may lead to low quality friendships.

Gender and Predictors of Friendship Maintenance, Dissolution, and Quality

Overall, the features of friendships that predicted friendship maintenance or dissolution and friendship quality after problems were very similar for girls and boys. There were, however, some gender differences in the features that predicted friendship maintenance, dissolution, and quality following problems. For girls only, friendships that were closer before problems were also higher in quality following problems. Consistent with previous findings, girls may place greater emphasis on trust and intimate communication (components of closeness in the present investigation) (e.g., Field et al., 1995; Hartup, 1993; Raja et al., 1992) as compared to boys. Thus, girls would value friendships in which such features were present. They may work to maintain the high quality of such friendships. Furthermore, the closeness of their friendships may allow girls to work through problems when problems occur. Also consistent with previous research (e.g., Field et al., 1995; Hartup, 1993; Raja et al., 1992), boys may not place as much emphasis on trust and communication in friendships.

Length of friendships before problems predicted friendship dissolution for girls but not for boys. Because girls' friendships are generally more close and intimate than are boys' friendships (Field et al., 1995; Hartup, 1993; Raja et al., 1992) and because intimate friendships may take time to develop, length of friendship may be more important to girls than to boys. Thus, girls who remain friends for a long time may be likely to maintain friendships because they have strong relationships with their friends. 
On the other hand, boys may not form such intimate relationships; as a result, having time to strengthen their relationships would not be predictive of friendship maintenance.

For boys, but not for girls, approval of friends' personal characteristics predicted overall friendship quality following problems. Perhaps this finding suggests that girls are less interested in their friends' specific characteristics and more interested in their friendship features (e.g., common experiences; trust; intimacy) as compared to boys.

Gender similarities were also found in the factors that predicted friendship maintenance or dissolution and friendship quality following problems. Approval of personal characteristics predicted friendship dissolution following problems for both girls and boys. Furthermore, expected ease of finding new friends was an important predictor of friendship quality following problems for both girls and boys.

\section{Summary}

In general, early adolescents who approved of their friends' personal characteristics before problems occurred were likely to maintain friendships and to have high quality friendships following problems. Thus, in addition to features of friendships, characteristics of individual friends predict friendship outcomes. Length of the friendship was an important predictor of girls' friendship dissolution after problems, and expected ease of finding new friends was an important predictor of friendship quality following problems. Also, there was some indication that features of the friendships such as closeness are important for understanding of girls' friendship quality following problems.

\section{Causes of Friendship Problems and Dissolution}

Findings suggest that, overall, early adolescents do not necessarily end friendships for the same reasons that they have problems with friends. For example, when early 
adolescents were asked to tell what caused their friendships to end, a lack of common experiences was the most common reported cause of terminated friendships. However, few early adolescents reported that a lack of common experiences was the cause of friendship problems. Thus, friendships appear to end when early adolescents do not have opportunities to do things together. Thus, if one's friend moved to a different school, joined a different sports team, or was placed into a different classroom, the friendship was likely to dissolve. However, friends rarely reported having problems due to a lack of common experiences, perhaps because a lack of common experiences instead led to relationship dissolution. It is important to note that many early adolescents reported that a lack of common experiences contributed to friendships that had already ended, but ratings of the extent to which common experiences were shared did not predict whether friendships would end following problems. Thus, when asked to think about dissolved friendships, early adolescents think about common experiences. However, when asked to think about problems with friends, early adolescents tend to identify problems that are not related to common experiences.

Communication was the reported cause of many more friendship problems than friendship endings. It is likely that this finding is related to the ease with which communication issues could be resolved. Specifically, perhaps early adolescents did not end friendships following communication problems, because their communication issues were relatively easy to resolve. For example, friends could easily resolve the problem of thinking that a friend intended to come over after school by talking about the misunderstanding. It is likely that many early adolescents experience communication problems with their friends, because they assume that they understand things in the same 
ways that others do. Friends may not talk about events that take place in their daily lives, because they think that their friends already know what is happening.

Very few participants ended friendships because of reasons that fell into the other category, but more experienced other types of problems. Causes of problems that fell into the other category included responses such as, "He was having a bad day," "She fought with her mom," and "He did not wake up." Such passing concerns may lead to acute friendship problems. However, it is unlikely that such occurrences would be reasons to terminate a friendship. It seems that the early adolescents recognized that such issues were temporary and not reasons to end friendships.

\section{Gender Differences}

Of the participants who identified trust as a cause of friendship problems, most were girls. It is not surprising that girls were more likely to identify problems with trust than were boys. This is because girls provide more help, support, and guidance to their friends than do boys (Jones \& Costin, 1995; Parker \& Asher, 1993); thus, girls likely value trust in their relationships more than do boys.

No other gender differences in causes of problems were found, and no gender differences were found in causes of friendship dissolution. This finding was unexpected. Boys were expected to have friendship problems and to end friendships due to a lack of common experiences more often than were girls, because activities of mutual interest are more central to boys' friendships than to girls' friendships (Wheeler et al., 1983; Zarbatany et al., 1990). Also, girls were expected to end friendships and have friendship problems due to communication issues more often than were boys. This was because girls often experience more intimacy, which is one aspect of communication, in their 
friendships (Field et al., 1995; Hartup, 1993; Raja et al., 1992). Lack of expected gender differences suggests that early adolescent girls and boys may value many of the same aspects of friendship relationships (e.g., common experiences; communication). Perhaps participants in the sample were not old enough to show expected adolescent differences. It is also possible that if more problems or more friendships were examined for each participant, differences would have been found. Perhaps boys and girls report similar problems when they are asked to describe only one problem, but boys and girls may experience different problems overall.

\section{Limitations and Future Directions}

One limitation of the present study is the retrospective self-report nature of the data. That is, early adolescents reported information about friendship problems and break-ups that occurred about 2-3 months before they completed the questionnaires. It is possible that early adolescents' responses were affected by the amount of time that passed between the events they described and their completing the questionnaires. Participants may not have remembered all of the events that surrounded their friendship problems or endings. Also, early adolescents may have described friendships as they were experienced at the time of the study instead of the way in which the friendships were experienced at the time of the friendship problems. That is, early adolescents may have reconstructed their memories of the events so that memories were consistent with their current friendship experiences. For example, one finding in this study was that early adolescents who did not like their friends' personal characteristics before friendship problems were likely to experience friendship termination. However, it is possible that individuals who were no longer friends reported that they did not like their friends in the 
first place. Given the current methods, it is impossible to determine if participants actually did like their friends before their relationships ended. Future research should be conducted in a prospective manner so that friendship features can be assessed before problems occur in friendships. Outcomes can then be determined, and the relationship between friendship features and outcome can be better understood.

Another limitation of the study is that participants only described one problem with one friend and one friendship that ended. Thus, findings may not represent general problems that early adolescents experience with their friends and acquaintances; instead, findings only suggest information about problems that participants remembered or about the problems they felt were the most important. Participants indicated that the problems they described were of medium importance and that it was fairly important that they keep the friends with whom they experienced problems. Future research could examine more types of problems (i.e., less important and more important problems) that early adolescents experience with their friends to determine if the importance of problems influences the association between friendship features and friendship outcomes following problems. Also, future research could compare different types of friendships (i.e., important or best friends and less significant friends) to determine if the same results would be found for a variety of individuals' friendships. Future research could also consider possible changes in the hierarchies of friendship relationships. Specifically, research could explore individuals who maintain their friendships but at new levels. For example, adolescents' friendships could be studied to determine if problems lead friendships to change in status (e.g., best friends become good friends). 
The sample was fairly homogenous in that most participants were White and from well-educated families. It would be beneficial for future research to identify early adolescents from different backgrounds to determine if all early adolescents experience friendship problems and friendship dissolution in the same ways. Friendship studies typically do not include comparisons of individuals from different backgrounds, so it is unclear if significant differences based on background exist. It is also important to assess friendship maintenance and dissolution for individuals of different ages. Previous research has typically focused on children's and adolescents' friendships and adults' romantic relationships. However, it is important to determine if different features are important in different types of relationships or if the same features are important to all types of relationships.

It should also be noted that friendship dissolution is not necessarily detrimental to early adolescents. That is, sometimes friendship dissolution is positive. If friendships are not rewarding for individuals or if individuals get into trouble with their friends, then it can be beneficial to terminate the friendships. Future research should address whether different friendship features are important to friendships of differing levels of quality. That is, are there associations between overall friendship quality before problems occur and friendship maintenance or dissolution and friendship quality following problems?

\section{Conclusion}

Expected ease of finding a new friend, approval of friends' personal characteristics, and length of friendships predicted friendship outcomes for early adolescents. Thus, early adolescents' friendships appear to end for the same reasons that other types of relationships (i.e., adults' friendships; romantic relationships) end. This 
finding suggests that future research on early adolescent friendship could draw from findings of other types of relationship studies. Furthermore, early adolescent friends report different causes of friendship problems and causes of friendship dissolution. Thus, it is important to consider friendship dissolution separately from friendship conflicts.

Finally, some of the same friendship features that are associated with friendship maintenance or high-quality friendships are also predictive of friendship dissolution or low-quality friendships after problems occur in early adolescent friendships. That is, a lack of some positive friendship features predicts friendship dissolution or low-quality friendships. 


\section{References}

Aboud, F. E., \& Mendelson, M. J. (1996). Determinants of friendship selection and quality: Developmental perspectives. In W. M. Bukowski, A. F. Newcomb, \& W. W. Hartup (Eds.), The company they keep: Friendship in childhood and adolescence (pp. 87-112). New York: Cambridge University Press.

Akers, J. F., Jones, R. M., \& Coyl, D. D. (1998). Adolescent friendship pairs:

Similarities in identity status development, behaviors, attitudes, and intentions. Journal of Adolescent Research, 13, 178-201.

Auhagen, A. E. (1996). Adult friendship. In A. E. Auhagen, \& M. von Salisch (Eds.), The Diversity of Human Relationships (pp. 229-247). New York: Cambridge University Press.

Azmitia, M., Lippman, D. L., \& Ittel, A. (1999). On the relation of personal experience to early adolescents' reasoning about best friendship deterioration. Social Development, 8, 275-291.

Berndt, T. J. (1999). Friends' influence on students' adjustment to school. Educational Psychologist, 34, 15-28.

Berndt, T. J., \& Das, R. (1987). Effects of popularity and friendship on perceptions of the personality and social behavior of peers. Journal of Early Adolescence, 7, 429439.

Berndt, T. J., Hawkins, J. A., \& Hoyle, S. G. (1986). Changes in friendship during a school year: Effects on children's and adolescents' impressions of friendship and sharing with friends. Child Development, 57, 1284-1297.

Berndt, T. J., \& Hoyle, S. G. (1985). Stability and change in childhood and adolescent 
friendships. Developmental Psychology, 21, 1007-1015.

Buhrmester, D. (1990). Intimacy of friendship, interpersonal competence, and adjustment during preadolescence and adolescence. Child Development, 61, 1101-1111.

Buhrmester, D., \& Furman, W. (1987). The development of companionship and intimacy. Child Development, 58, 1101-1113.

Bukowski, W. M., Hoza, B., \& Boivin, M. (1994). Measuring friendship quality during pre- and early adolescence: The development and psychometric properties of the friendship qualities scale. Journal of Social and Personal Relationships, 11, 471484.

Bukowski, W. M., Newcomb, A. F., \& Hartup, W. W. (1996). Friendship and its significance in childhood and adolescence: Introduction and comment. In W. M. Bukowski, A. F. Newcomb, \& W. W. Hartup (Eds.), The company they keep: Friendship in childhood and adolescence (pp. 1-15). New York: Cambridge University Press.

Bukowski, W. M., Sippola, L. K., \& Newcomb, A. F. (2000). Variations in patterns of attraction to same-and other-sex peers during early adolescence. Developmental Psychology, 36, 147-154.

Claes, M. (1994). Friendship characteristics of adolescents referred for psychiatric treatment. Journal of Adolescent Research, 9, 180-192.

Csikszentmihalyi, M., \& Larson, R. (1984). Being adolescent: Conflict and growth in the teenage years (pp. 155-175). New York: Basic Books.

Devlin, A. S. (1996). Survival skills training during freshman orientation: Its role in college adjustment. Journal of College Student Development, 37, 324-334. 
Erikson, E. H. (1963). Childhood and society ( $2^{\text {nd }}$ ed.). New York: Norton.

Fehr, B. (1999). Stability and commitment in friendships. In J. M. Adams, \& W. H. Jones (Eds.), Handbook of interpersonal commitment and relationship stability (pp.259-280). New York: Kluwer Academic/Plenum Publishers.

Felmlee, D., Sprecher, S., \& Bassin, E. (1990). The dissolution of intimate relationships: A hazard model. Social Psychology Quarterly, 53, 13-30.

Field, T., Lang, C., Yando, R., \& Bendell, D. (1995). Adolescents' intimacy with parents and friends. Adolescence, 30, 133-140.

Furman, W. (1984). Some observations on the study of personal relationships. In J. C. Masters, \& K. Yarkin-Levin (Eds.), Boundary areas in social and developmental psychology (pp. 15-42). Orlando: Academic Press.

Furman, W. (1996). The measurement of friendship perceptions: Conceptual and methodological issues. In W. M. Bukowski, A. F. Newcomb, \& W. W. Hartup (Eds.), The company they keep: Friendship in childhood and adolescence (pp. 4165). New York: Cambridge University Press.

Furman, W., \& Buhrmester, D. (1985). Children's perceptions of the personal relationships in their social networks. Developmental Psychology, 21, 1016-1022.

Gavin, L. A., \& Furman, W. (1996). Adolescent girls' relationships with mothers and best friends. Child Development, 67, 375-386.

Hamm, J. V. (2000). Do birds of a feather flock together? The variable bases for African American, Asian American, and European American Adolescents' selection of similar friends. Developmental Psychology, 36, 209-219.

Hartup, W. W. (1989). Social relationships and their developmental significance. 
American Psychologist, 44, 120-126.

Hartup, W. W. (1993). Adolescents and their friends. New directions for child development, 60, 3-22.

Hartup, W. W., French, D. C., Laursen, B., Johnston, M. K., \& Ogawa, J. R. (1993). Conflict and friendship relations in middle childhood: Behavior in a closed-field situation. Child Development, 64, 445-454.

Heiman, G. W. (1992). Basic statistics for the behavioral sciences (pp. 451-491). Boston: Houghton Mifflin.

Jiao, Z. (1999, April). Which students keep old friends and which become new friends across a school transition. Poster presented at the biennial meeting of the Society for Research in Child Development, Albuquerque, NM.

Jones, D. C., \& Costin, S. E. (1995). Friendship quality during preadolescence and adolescence: The contributions of relationship orientations, instrumentality, and expressivity. Merrill-Palmer Quarterly, 41, 517-535.

Kerns, K. A., Klepac, L., \& Cole, A. (1996). Peer relationships and preadolescents' perceptions of security in the child-mother relationship. Developmental Psychology, 32, 457-466.

Ladd, G. W., Kochenderfer, B. J., \& Coleman, C. C. (1996). Friendship quality as a predictor of young children's early school adjustment. Child Development, 67, 1103-1118.

Laursen, B., \& Collins, W. A. (1994). Interpersonal conflict during adolescence. Psychological Bulletin, 115, 197-209.

Lawhon, T. (1997). Encouraging friendships among children. Childhood Education, 73, 
228-231.

Mahoney, J. L., \& Cairns, R. B. (1997). Do extracurricular activities protect against early school dropout? Developmental Psychology, 33, 241-253.

Marcia, J. E. (1998). Optimal development from an Eriksonian perspective. In H. S. Friedman (Ed.), Encyclopedia of mental health (Vol. 3). San Diego: Academic Press.

Miller, P. M., Danaher, D. L., \& Forbes, D. (1986). Sex-related strategies for coping with interpersonal conflict in children aged five and seven. Developmental Psychology, $22,543-548$.

Newcomb, A. F., \& Bagwell, C. L. (1995). Children's friendship relations: A metaanalytic review. Psychological Bulletin, 117, 306-347.

Parker, J. G., \& Asher, S. R. (1993). Friendship and friendship quality in middle childhood: Links with peer group acceptance and feelings of loneliness and social dissatisfaction. Developmental Psychology, 29, 611-621.

Parker, J. G., \& Seal, J. (1996). Forming, losing, renewing, and replacing friendships: Applying temporal parameters to the assessment of children's friendship experiences. Child Development, 67, 2248-2268.

Paterson, J., Pryor, J., \& Field, J. (1995). Adolescent attachment to parents and friends in relation to aspects of self-esteem. Journal of Youth and Adolescence, 24, 365-376.

Raja, S. N., McGee, R., \& Stanton, W. R. (1992). Perceived attachments to parents and peers and psychological well-being in adolescence. Journal of Youth and Adolescence, 21, 471-485.

Rose, A. J., \& Asher, S. R. (1999). Children's goals and strategies in response to conflicts 
within a friendship. Developmental Psychology, 35, 69-79.

Rubin, K. H., Bukowski, W., \& Parker, J. G. (1998). Peer interactions, relationships, and groups. In W. Damon (Series Ed.) \& N. Eisenberg (Vol. Ed.), Handbook of child psychology: Vol. 3. Social, emotional, and personality development ( $5^{\text {th }}$ ed., pp. 619-700). New York: Wiley.

Rusbult, C. E. (1980). Satisfaction and commitment in friendships. Representative Research in Social Psychology, 11, 96-105.

Sansone, C., \& Berg, C. A. (1993). Adapting to the environment across the life span: Different process or different inputs? International Journal of Behavioral Development, 16, 215-241.

Selman, R. L., \& Schultz, L. H. (1990). Making a friend in Youth: Developmental theory and pair therapy. Chicago: University of Chicago.

Simpson, J. A. (1987). The dissolution of romantic relationships: Factors involved in relationship stability and emotional distress. Journal of Personality and Social Psychology, 53, 683-692.

Sprecher, S., \& Fehr, B. (1998). The dissolution of close relationships. In J. H. Harvey (Ed.), Perspectives on Loss (pp. 99-112). Philadelphia: Edwards Brothers.

Sroufe, L. A., Bennett, C., Englund, M., Urban, J., \& Shulman, S. (1993). The significance of gender boundaries in preadolescence: Contemporary corelates and antecedents of boundary violation and maintenance. Child Development, 64, 455466.

Strough, J., Swenson, L. M., \& Cheng, S. (2001). Friendship, gender, and preadolescents' 
representations of peer collaborative problem solving. Merrill-Palmer Quarterly, 47, 475-499.

U.S. Bureau of the Census. (1987). Classified index of industry and occupation: Final edition 1980. (Census Population Report PHC 80-R4). Washington, D.C.: Author.

Wentzel, K. R., \& Erdley, C. A. (1993). Strategies for making friends: Relations to social behavior and peer acceptance in early adolescence. Developmental Psychology, 29, 819-826.

Wheeler, L., Reis, H., \& Nezlek, J. (1983). Loneliness, social interaction, and sex roles. Journal of Personality and Social Psychology, 45, 943-953.

Wright, P. H., \& Keple, T. W. (1981). Friends and parents of a sample of high school juniors: An exploratory study of relationship intensity and interpersonal rewards. Journal of Marriage and the Family, 43, 559-570.

Youniss, J. (1999). Children's friendships and peer culture. In M. Woodhead, D. Faulkner, \& K. Littleton (Eds.), Making sense of social development (pp. 13-26). New York: Routledge.

Zarbatany, L., Hartmann, D. P., \& Rankin, D. B. (1990). The psychological functions of preadolescent peer activities. Child Development, 61, 1067-1080. 
Appendix A

Directions for Administering Questionnaires

\section{Directions for Administering Questionnaires}

Each student who has parental consent to complete the questionnaires should be given a folder containing all of the materials. The following directions should be given to the students:

You are being asked to answer some questions about your friends. Your answers will be given to a WVU student who is working on a project to find out about opinions people have about friends. She also wants to find out what kind of problems people your age have with their friends and why some friendships end.

You can help her with her project by answering all of the questions about problems you have had with your friends and about why some of your friendships ended. There aren't any right or wrong answers to the questions. She just wants your ideas.

The first thing for you to do is to fill out something called an assent form. That is the first piece of paper in your folder. When you sign the form you are letting the person who is doing this project use your answers for the project. Your name will never be used in the project, just your answers.

(Read assent form)

After you have signed the form, please put it back in your folder.

Next, you will fill out the rest of the papers in the folder. Please do not put your name on any of the papers.

First, you will see a paper that says "Some information about you" at the top. After we are finished looking through the folders, you will answer those easy questions.

The second thing you see in the folder asks you to make a list of all of your good friends. Please just write the first name of each person. Last names are not needed. Then, write if each person is a boy or a girl. Finally, you are asked to rate each friend. Write a 1 if the person is a good friend, a 2 if they are a really good friend, and a 3 if they are your best friend. You don't have to use all of the lines for friends. It's OK if you have a short list.

The third thing in your folder is a packet that says "Problems with Friends" on the first page. You are asked to write about a problem you have had with one of your friends. For these questions, remember that not all problems are really big deals. You can have a small problem with a friend without having a big fight. If you can't think of a big problem you have had with a friend, you could describe a small disagreement, hassle, or conflict. 
The last thing you will see in the folder is another packet that says "Friendship Endings" on the first page. This packet asks you a bunch of questions about someone who used to be your friend but isn't anymore. Remember that friendships don't have to end with fights. People can stop being friends for lots of reasons. Maybe you had a friend a long time ago who you don't see any more, or maybe your friend moved to a new school. If something like that happened, you can write about that.

As you go through all the questions, try to answer all of them. If you aren't sure what to put, choose an answer that is closest to the way you feel. There are no good or bad answers. The person who is doing the project just wants to know your opinions. Remember that the only people who will see your answers are the people who are working on this project. No one at school or at home will see your answers. Please work on the questionnaires by yourselves, and do not talk to other students while you are working.

When you are finished with all of the questions, please put all of the papers back into your folder.

Thank you for helping with this project. 
Appendix B

\section{Some Information About You}

Today's date

Are you a male or a female?

male

female

How old are you?

Do you consider yourself to be: (Please check one)

$\begin{array}{lr}\text { White/Caucasian } & \text { Black/African American } \_ \text {Asian } \\ \text { Hispanic } & \text { Other (If Other, please specify) }\end{array}$

What grade are you in?

When is your birthday?

Day __ Month___ Year___ 
Please list the first names of all of your good friends. Also, please tell if each friend is a boy or a girl.

Name

$\overline{\bar{L}} \overline{ } \overline{ }$
Boy or Girl
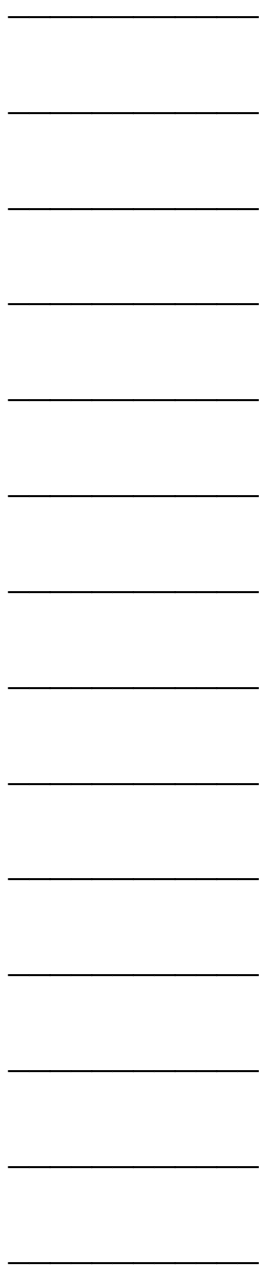
Appendix C
Friendship Problems Questionnaire

\section{Problems With Friends}

Please think about a problem (disagreement/hassle/argument/conflict) you had with a friend within the last year. You may think of a problem you had with someone who is still your friend or with someone who is not your friend anymore.

What are this friend's initials?

Is this friend a boy or a girl?

1. Explain everything that happened in the problem. Give many details, because you are explaining the problem to someone who doesn't know anything about it.

2. In this situation, what was the one main problem?

3. In this situation, what was the main cause of the problem? 
4. When the problem happened, what was your goal? In other words, what did you want to happen?

5. How well do you think you met this goal?

$\begin{array}{lcccc}1 & 2 & 3 & 4 & 5 \\ \text { not well } & \text { a little bit } & \text { in the middle } & \text { pretty well } & \text { very well } \\ \text { at all } & \text { well } & & & \end{array}$

6. How long ago did this problem happen? (Circle one)

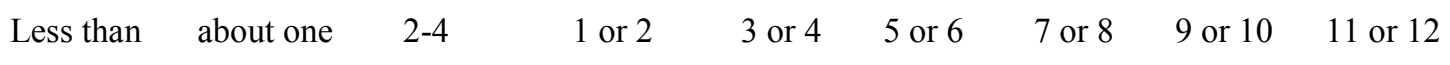

1 week week weeks months months months months months months

7. How important was it to you to keep this friendship?

$\begin{array}{llccc}1 & 2 & 3 & 4 & 5 \\ \text { not at all } & \text { a little bit } & \text { in the middle } & \text { pretty } & \text { very } \\ \text { important } & \text { important } & & \text { important } & \text { important }\end{array}$

8. How important was the problem?

$\begin{array}{lcccc}1 & 2 & 3 & 4 & 5 \\ \text { not at all } & \text { a little bit } & \text { in the middle } & \text { pretty } & \text { very } \\ \text { important } & \text { important } & & \text { important } & \text { important }\end{array}$

9. Are you still friends with the person? (Please check one.)

Yes

No

10. What did you do to solve the problem? Please give as many details as you remember. 
11. Did you expect the problem to happen or was it a surprise?

$\begin{array}{lcccc}1 & 2 & 3 & 4 & 5 \\ \text { did not expect } & \begin{array}{l}\text { expected it } \\ \text { at all }\end{array} & \text { in the middle } & \begin{array}{c}\text { expected } \\ \text { quite a bit }\end{array} & \begin{array}{c}\text { completely } \\ \text { expected }\end{array}\end{array}$

12. If you answered 2 or above to question 10, did you do anything to try to stop the problem from happening?

Yes

13. If you answered Yes to question 11, what did you do to try to stop the problem from happening?

14. If you answered No to question 11, why didn't you do anything to try to stop the problem from happening?

15. Overall, how well do you think you solved the problem?

$\begin{array}{lcccc}1 & 2 & 3 & 4 & 5 \\ \text { not well } & \text { a little bit } & \text { in the middle } & \text { pretty well } & \text { very well } \\ \text { at all } & \text { well } & & \end{array}$

16. How much of the problem was your fault?

$\begin{array}{ccccl}1 & 2 & 3 & 4 & 5 \\ \text { none } & \text { a little bit } & \text { in the middle } & \text { pretty much } & \text { all }\end{array}$

17. How much of the problem was your friend's fault?

$\begin{array}{ccccl}1 & 2 & 3 & 4 & 5 \\ \text { none } & \text { a little bit } & \text { in the middle } & \text { pretty much } & \text { all }\end{array}$


18. How much of the problem was both your fault and your friend's fault?

$\begin{array}{ccccl}1 & 2 & 3 & 4 & 5 \\ \text { none } & \text { a little bit } & \text { in the middle } & \text { pretty much } & \text { all }\end{array}$

19. How long had you and your friend been friends before the problem happened? Circle the number of years you had been friends.
Less than
234
1 year
More than 10
years

20. Before the problem, how much did you and your friend tell each other how you were feeling?

$\begin{array}{lcccc}1 & 2 & 3 & 4 & 5 \\ \text { not at all } & \text { sometimes } & \text { in the middle } & \text { quite a bit } & \text { all the time }\end{array}$

21. After the problem, how much did you and your friend tell each other how you were feeling?
1
2
not at all sometimes in the middle quite a bit all the time
3
not at all sometimes in the middle quite a bit all the time
4
not at all sometimes in the middle quite a bit all the time
5

22. Before the problem, how much did you and your friend tell each other what you were thinking?
1
2
3
4
5
not at all sometimes
in the middle
quite a bit
all the time

23. After the problem, how much did you and your friend tell each other what you were thinking?
$\begin{array}{lc}1 & 2 \\ \text { not at all } & \text { sometimes }\end{array}$
3
in the middle
4
quite a bit
5
not at all sometimes in the middle quite a bit all the time

24. How much did you trust your friend before the problem?
1
2
3
4
5
not at all
a little bit
in the middle
pretty much
very much

25. How much did you trust your friend after the problem?
1
2
a little bit
3
in the middle
4
5
pretty much
very much 
26. Before the problem happened, how much did you and your friend try to make your friendship as good as it could be?

$\begin{array}{lcccc}1 & 2 & 3 & 4 & 5 \\ \text { not at all } & \text { a little bit } & \text { in the middle } & \text { pretty much } & \text { very much }\end{array}$

27. After the problem happened, how much did you and your friend try to make your friendship as good as it could be?

$\begin{array}{lcccc}1 & 2 & 3 & 4 & 5 \\ \text { not at all } & \text { a little bit } & \text { in the middle } & \text { pretty much } & \text { very much }\end{array}$

28. How much did you and your friend help each other before the problem?

$\begin{array}{lcccc}1 & 2 & 3 & 4 & 5 \\ \text { not at all } & \text { a little bit } & \text { in the middle } & \text { pretty much } & \text { very much }\end{array}$

29. How much did you and your friend help each other after the problem?

$\begin{array}{lcccc}1 & 2 & 3 & 4 & 5 \\ \text { not at all } & \text { a little bit } & \text { in the middle } & \text { pretty much } & \text { very much }\end{array}$

30. Before the problem, how much did you and your friend like to do the same things?

$\begin{array}{lcccc}1 & 2 & 3 & 4 & 5 \\ \text { not at all } & \text { a little bit } & \text { in the middle } & \text { pretty much } & \text { very much }\end{array}$

31. After the problem, how much did you and your friend like to do the same things?

$\begin{array}{lcccc}1 & 2 & 3 & 4 & 5 \\ \text { not at all } & \text { a little bit } & \text { in the middle } & \text { pretty much } & \text { very much }\end{array}$

32. Before the problem, how often did you and your friend do things together?

$\begin{array}{lcccc}1 & 2 & 3 & 4 & 5 \\ \text { never } & \text { a little bit } & \text { in the middle } & \text { pretty often } & \text { almost always }\end{array}$

33. After the problem, how often did you and your friend do things together?

$\begin{array}{lcccc}1 & 2 & 3 & 4 & 5 \\ \text { never } & \text { a little bit } & \text { in the middle } & \text { pretty often } & \text { almost always }\end{array}$


34. Before the problem, how much did you put into the friendship?

$\begin{array}{ccccc}1 & 2 & 3 & 4 & 5 \\ \text { nothing at all } & \text { a little bit } & \text { in the middle } & \text { pretty much } & \text { very much }\end{array}$

35. After the problem, how much did you put into the friendship?

$\begin{array}{ccccc}1 & 2 & 3 & 4 & 5 \\ \text { nothing at all } & \text { a little bit } & \text { in the middle } & \text { pretty much } & \text { very much }\end{array}$

36. Before the problem, how much did your friend put into the friendship?

$\begin{array}{ccccc}1 & 2 & 3 & 4 & 5 \\ \text { nothing at all } & \text { a little bit } & \text { in the middle } & \text { pretty much } & \text { very much }\end{array}$

37. After the problem, how much did your friend put into the friendship?

$\begin{array}{ccccc}1 & 2 & 3 & 4 & 5 \\ \text { nothing at all } & \text { a little bit } & \text { in the middle } & \text { pretty much } & \text { very much }\end{array}$

38. Before the problem, how much did you get out of the friendship?

$\begin{array}{ccccc}1 & 2 & 3 & 4 & 5 \\ \text { nothing at all } & \text { a little bit } & \text { in the middle } & \text { pretty much } & \text { very much }\end{array}$

39. After the problem, how much did you get out of the friendship?

$\begin{array}{ccccc}1 & 2 & 3 & 4 & 5 \\ \text { nothing at all } & \text { a little bit } & \text { in the middle } & \text { pretty much } & \text { very much }\end{array}$

40. Before the problem, how much did your friend get out of the friendship?

$\begin{array}{ccccc}1 & 2 & 3 & 4 & 5 \\ \text { nothing at all } & \text { a little bit } & \text { in the middle } & \text { pretty much } & \text { very much }\end{array}$

41. After the problem, how much did your friend get out of the friendship?

$\begin{array}{ccccc}1 & 2 & 3 & 4 & 5 \\ \text { nothing at all } & \text { a little bit } & \text { in the middle } & \text { pretty much } & \text { very much }\end{array}$

42. Before the problem, how much did you like the kind of person your friend was?

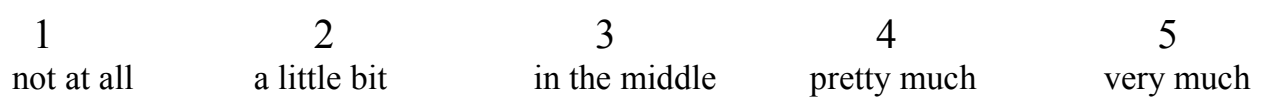


43. After the problem, how much did you like the kind of person your friend was?

$\begin{array}{ccccc}1 & 2 & 3 & 4 & 5 \\ \text { not at all } & \text { a little bit } & \text { in the middle } & \text { pretty much } & \text { very much }\end{array}$

44. How much time did you spend with your friend before the problem?

$\begin{array}{lcccc}1 & 2 & 3 & 4 & 5 \\ \text { none at all } & \text { a little bit } & \text { in the middle } & \text { pretty much } & \text { very much }\end{array}$

45. How much time did you spend with your friend after the problem?

$\begin{array}{lcccc}1 & 2 & 3 & 4 & 5 \\ \text { none at all } & \text { a little bit } & \text { in the middle } & \text { pretty much } & \text { very much }\end{array}$

46. If you and the friend you described the problem with were no longer friends, how easy would it be to find a new friend?

$\begin{array}{lcccc}1 & 2 & 3 & 4 & 5 \\ \text { impossible } & \text { a little hard } & \text { in the middle } & \text { pretty easy } & \text { extremely easy }\end{array}$

47. How good of friends were you before the problem?

$\begin{array}{lcccc}1 & 2 & 3 & 4 & 5 \\ \text { not friends } & \text { OK friends } & \text { in the middle } & \begin{array}{c}\text { pretty good } \\ \text { friends }\end{array} & \begin{array}{c}\text { best } \\ \text { friends }\end{array}\end{array}$

48. How good of friends were you after the problem?

$\begin{array}{lcccc}1 & 2 & 3 & 4 & 5 \\ \text { not friends } & \text { OK friends } & \text { in the middle } & \text { pretty good } & \text { best } \\ & & \text { friends } & \text { friends }\end{array}$

49. If this problem happened again, how likely would you be to remain friends with the person?

$\begin{array}{lcccc}1 & 2 & 3 & 4 & 5 \\ \text { not at all } & \text { a little bit } & \text { in the middle } & \text { pretty likely } & \text { very likely } \\ \text { likely } & \text { likely } & & \end{array}$

50. If problems like the one you described started to happen all the time, how likely would you be to remain friends with the person?

$\begin{array}{lcccc}1 & 2 & 3 & 4 & 5 \\ \text { not at all } & \text { a little bit } & \text { in the middle } & \text { pretty likely } & \text { very likely } \\ \text { likely } & \text { likely } & & \end{array}$


51. How happy did the problem make you feel?

$\begin{array}{ccccc}1 & 2 & 3 & 4 & 5 \\ \text { very unhappy } & \text { a little unhappy } & \text { in the middle } & \text { a little happy } & \text { very happy }\end{array}$

52. How angry did the problem make you feel?

$\begin{array}{lcccc}1 & 2 & 3 & 4 & 5 \\ \text { very angry } & \text { pretty angry } & \text { in the middle } & \text { slightly angry } & \text { not angry at all }\end{array}$

53. How sad did the problem make you feel?

$\begin{array}{ccccc}1 & 2 & 3 & 4 & 5 \\ \text { not at all sad } & \text { a little sad } & \text { in the middle } & \text { pretty sad } & \text { very sad }\end{array}$


Appendix D

Friendship Endings Questionnaire

\section{Friendship Endings}

Please think of a person who used to be your friend but who is not your friend anymore.

What are this person's initials? Is this person a boy or a girl?

1. What happened that caused your friendship to end? Please give as many details as you can. You are describing this to someone who knows nothing about the friendship.

2. What was the main cause of the friendship ending? 
3. When the friendship ended, what was your goal? In other words, what did you want to happen?

4. How well do you think you met this goal?

$\begin{array}{lcccc}1 & 2 & 3 & 4 & 5 \\ \text { not well } & \text { a little bit } & \text { in the middle } & \text { pretty well } & \text { very well } \\ \text { at all } & \text { well } & & & \end{array}$

5. How long ago did the friendship end? (Circle one)

$\begin{array}{llllllll}\text { Less than } & \text { about } & 2-4 & 1-3 & 4-6 & 7-9 & 10-12 & \text { more than } \\ 1 \text { week } & 1 \text { week } & \text { weeks } & \text { months } & \text { months } & \text { months } & \text { months } & 1 \text { year }\end{array}$

6. How important was it to you to keep this friendship?

$\begin{array}{lcccc}1 & 2 & 3 & 4 & 5 \\ \text { not at all } & \text { a little bit } & \text { in the middle } & \text { pretty } & \text { very }\end{array}$

7. Did you expect the friendship to end or was it a surprise?

$\begin{array}{lcccc}1 & 2 & 3 & 4 & 5 \\ \text { did not expect } & \begin{array}{c}\text { expected it } \\ \text { a little bit }\end{array} & \text { in the middle } & \begin{array}{c}\text { expected } \\ \text { quite a bit }\end{array} & \begin{array}{c}\text { completely } \\ \text { expected }\end{array}\end{array}$

8. If you answered 2 or above to question 7 , did you do anything to try to stop the friendship from ending?

$$
\text { Yes__ No }
$$

9. If you answered Yes to question 8 , what did you do to try to stop the friendship from ending? 
10. If you answered No to question 8 , why didn't you do anything to stop the friendship from ending?

11. How much would you say that ending the friendship was your idea?

$\begin{array}{ccccc}1 & 2 & 3 & 4 & 5 \\ \text { not at all } & \text { not very much } & \text { in the middle } & \text { pretty much } & \text { completely }\end{array}$

12. How much would you say that ending the friendship was your friend's idea?

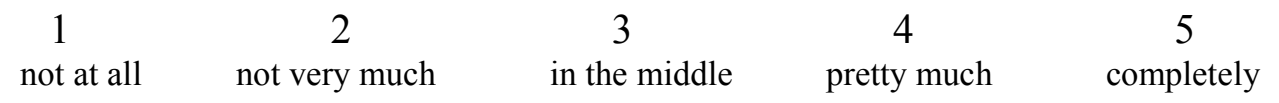

13. How much would you say that ending the friendship was not your idea or your friend's idea?

$\begin{array}{lcccc}1 & 2 & 3 & 4 & 5 \\ \text { not at all } & \text { not very much } & \text { in the middle } & \text { pretty much } & \text { completely }\end{array}$

14. How long had you and your friend been friends before your friendship ended? Circle the number of years you had been friends.
Less than
12
45
$\begin{array}{lll}6 & 7 & 8\end{array}$
1 year
10 More than 10
years

15. Before the friendship ended, how much did you and your friend tell each other how you were feeling?

$\begin{array}{ccccc}1 & 2 & 3 & 4 & 5 \\ \text { not at all } & \text { sometimes } & \text { in the middle } & \text { quite a bit } & \text { all the time }\end{array}$

16. After the friendship ended, how much did you and your friend tell each other how you were feeling?

$\begin{array}{ccccc}1 & 2 & 3 & 4 & 5 \\ \text { not at all } & \text { sometimes } & \text { in the middle } & \text { quite a bit } & \text { all the time }\end{array}$


17. Before the friendship ended, how much did you and your friend tell each other what you were thinking?

$\begin{array}{lcccc}1 & 2 & 3 & 4 & 5 \\ \text { not at all } & \text { sometimes } & \text { in the middle } & \text { quite a bit } & \text { all the time }\end{array}$

18. After the friendship ended, how much did you and your friend tell each other what you were thinking?

$\begin{array}{lcccc}1 & 2 & 3 & 4 & 5 \\ \text { not at all } & \text { sometimes } & \text { in the middle } & \text { quite a bit } & \text { all the time }\end{array}$

19. How much did you trust your friend before the friendship ended?

$\begin{array}{lcccc}1 & 2 & 3 & 4 & 5 \\ \text { not at all } & \text { a little bit } & \text { in the middle } & \text { pretty much } & \text { very much }\end{array}$

20. How much did you trust your friend after your friendship ended?

$\begin{array}{lcccc}1 & 2 & 3 & 4 & 5 \\ \text { not at all } & \text { a little bit } & \text { in the middle } & \text { pretty much } & \text { very much }\end{array}$

21. Before your friendship ended, how much did you and your friends try to make your friendship as good as it could be?

$\begin{array}{lllll}1 & 2 & 3 & 4 & 5\end{array}$

not at all a little bit in the middle pretty much very much

22. How much did you and your friend help each other before your friendship ended?

$\begin{array}{lcccc}1 & 2 & 3 & 4 & 5 \\ \text { not at all } & \text { a little bit } & \text { in the middle } & \text { pretty much } & \text { very much }\end{array}$

23. How much did you and your friend help each other after your friendship ended?

$\begin{array}{lcccc}1 & 2 & 3 & 4 & 5 \\ \text { not at all } & \text { a little bit } & \text { in the middle } & \text { pretty much } & \text { very much }\end{array}$

24. Before your friendship ended, how much did you and your friend like to do the same things?

$\begin{array}{ccccc}1 & 2 & 3 & 4 & 5 \\ \text { not at all } & \text { a little bit } & \text { in the middle } & \text { pretty much } & \text { very much }\end{array}$


25. After your friendship ended, how much did you and your friend like to do the same things?

$\begin{array}{ccccc}1 & 2 & 3 & 4 & 5 \\ \text { not at all } & \text { a little bit } & \text { in the middle } & \text { pretty much } & \text { very much }\end{array}$

26. Before your friendship ended, how often did you and your friend do things together?

$\begin{array}{lcccc}1 & 2 & 3 & 4 & 5 \\ \text { never } & \text { a little bit } & \text { in the middle } & \text { pretty often } & \text { almost always }\end{array}$

27. After your friendship ended, how often did you and your friend do things together?

$\begin{array}{lcccc}1 & 2 & 3 & 4 & 5 \\ \text { never } & \text { a little bit } & \text { in the middle } & \text { pretty often } & \text { almost always }\end{array}$

28. Before your friendship ended, how much did you put into the friendship?

$\begin{array}{ccccc}1 & 2 & 3 & 4 & 5 \\ \text { nothing at all } & \text { a little bit } & \text { in the middle } & \text { pretty much } & \text { very much }\end{array}$

29. Before the friendship ended, how much did your friend put into the friendship?

$\begin{array}{ccccc}1 & 2 & 3 & 4 & 5 \\ \text { nothing at all } & \text { a little bit } & \text { in the middle } & \text { pretty much } & \text { very much }\end{array}$

30. Before your friendship ended, how much did you get out of the friendship?

$\begin{array}{ccccc}1 & 2 & 3 & 4 & 5 \\ \text { nothing at all } & \text { a little bit } & \text { in the middle } & \text { pretty much } & \text { very much }\end{array}$

31. Before your friendship ended, how much did your friend get out of the friendship?

$\begin{array}{ccccc}1 & 2 & 3 & 4 & 5 \\ \text { nothing at all } & \text { a little bit } & \text { in the middle } & \text { pretty much } & \text { very much }\end{array}$

32. Before your friendship ended, how much did you like the kind of person your friend was?

$\begin{array}{ccccc}1 & 2 & 3 & 4 & 5 \\ \text { not at all } & \text { a little bit } & \text { in the middle } & \text { pretty much } & \text { very much }\end{array}$


33. After your friendship ended, how much did you like the kind of person your friend was?

$\begin{array}{ccccc}1 & 2 & 3 & 4 & 5 \\ \text { not at all } & \text { a little bit } & \text { in the middle } & \text { pretty much } & \text { very much }\end{array}$

34. How much time did you spend with your friend before your friendship ended?

$\begin{array}{lcccc}1 & 2 & 3 & 4 & 5 \\ \text { none at all } & \text { a little bit } & \text { in the middle } & \text { pretty much } & \text { very much }\end{array}$

35. How much time did you spend with your friend after your friendship ended?
none at all
2
a little bit
3
in the middle
4
pretty much
very much

36. After your friendship ended, how easy was it for you to find a new friend?

$\begin{array}{lcccc}1 & 2 & 3 & 4 & 5 \\ \text { impossible } & \text { pretty hard } & \text { in the middle } & \text { pretty easy } & \text { extremely easy }\end{array}$

37. How good of friends were you before your friendship ended?

$\begin{array}{lcccc}1 & 2 & 3 & 4 & 5 \\ \text { not friends } & \text { OK friends } & \text { in the middle } & \text { pretty good } & \text { friends } \\ & & & & \text { best } \\ & & & \end{array}$

38. Did you and your friend become friends again after your friendship ended?

Yes No

39. If you answered No to question 21, do you think that you will become friends again in the future?

Yes No

40. How happy did ending the friendship make you feel?

$\begin{array}{lcccc}1 & 2 & 3 & 4 & 5 \\ \text { very unhappy } & \text { a little unhappy } & \text { in the middle } & \text { a little happy } & \text { very happy }\end{array}$

41. How angry did ending the friendship make you feel?
1
2
3
4
5
very angry pretty angry in the middle slightly angry not angry at all 
42. How sad did ending the friendship make you feel?

$\begin{array}{lcccc}1 & 2 & 3 & 4 & 5 \\ \text { not sad at all } & \text { a little sad } & \text { in the middle } & \text { pretty sad } & \text { very sad }\end{array}$


Table 1

Descriptive Statistics for Friendship Features Before Friendship Problems

\begin{tabular}{lccc} 
Friendship Feature & Mean & Standard Deviation & Range \\
\hline Length of Friendship & 3.65 & 3.06 & $0-11$ \\
Girls & 3.72 & 2.91 & $0-11$ \\
Boys & 3.68 & 2.99 & $0-11$ \\
Overall & & & \\
Personal Characteristics & 3.96 & 1.10 & $2-5$ \\
Girls & 3.73 & 1.04 & $1-5$ \\
Boys & 3.87 & 1.08 & $1-5$ \\
Overall & & &
\end{tabular}

Ease of Finding a New

Friend

Girls

3.78

1.13

$1-5$

Boys

3.95

1.07

$1-5$

Overall

3.85

1.11

$1-5$

Closeness

\begin{tabular}{lccc} 
Girls & 3.53 & 1.04 & $1-5$ \\
Boys & 3.02 & 0.86 & $1-5$ \\
Overall & 3.31 & 1.00 & $1-5$ \\
\hline
\end{tabular}


Table 1 (continued)

\begin{tabular}{lccc}
\hline Friendship Feature & Mean & Standard Deviation & Range \\
\hline Common & & & \\
Experiences & 3.74 & 1.05 & $2-5$ \\
$\quad$ Girls & 3.71 & 1.09 & $1-5$ \\
Boys & 3.73 & 1.07 & \\
Overall & & & \\
Balance of Rewards & & & $-5-+2$ \\
and Costs & & 0.97 & $-4-+3$ \\
Girls & -0.19 & 1.13 & $-4-+3$ \\
Boys & -0.15 & 1.03 & \\
Overall & -0.18 & & \\
\hline
\end{tabular}


Table 2

Correlations Among Friendship Features Before Problems and Friendship Outcomes

\begin{tabular}{lccccccccc}
\hline & 1 & 2 & 3 & 4 & 5 & 6 & 7 & 8 \\
\hline 1. Length of Friendship & & & & & & & & & \\
Girls & 1.00 & $.229 *$ & .008 & $.259 * *$ & -.058 & $.198 *$ & $-.292 * *$ & .156 \\
Boys & 1.00 & $.264 *$ & -.095 & $.294 *$ & .080 & $.518 * *$ & -.156 & .206 \\
Overall & 1.00 & $.239 * *$ & -.030 & $.257 * *$ & .003 & $.327 * *$ & $-.229 * *$ & $.177 *$
\end{tabular}

2. Personal Characteristics

$\begin{array}{llllllll}\text { Girls } & 1.00 & -.167 & .722 * * & .067 & .588^{* *} & -.336^{* *} & .466 * * \\ \text { Boys } & 1.00 & -.037 & .467 * * & -.218 & .622^{* *} & -.487 * * & .599 * * \\ \text { Overall } & 1.00 & -.124 & .631^{* *} & -.059 & .599 * * & -.407 * * & .512 * *\end{array}$

3. Ease of Finding a Friend

Girls

$\begin{array}{rrrrrr}1.00 & -.042 & .081 & .035 & .130 & -.288^{* *} \\ 1.00 & -.042 & -.039 & -.077 & .168 & -.267 *\end{array}$

Boys

(table continues) 
Table 2 (continued)

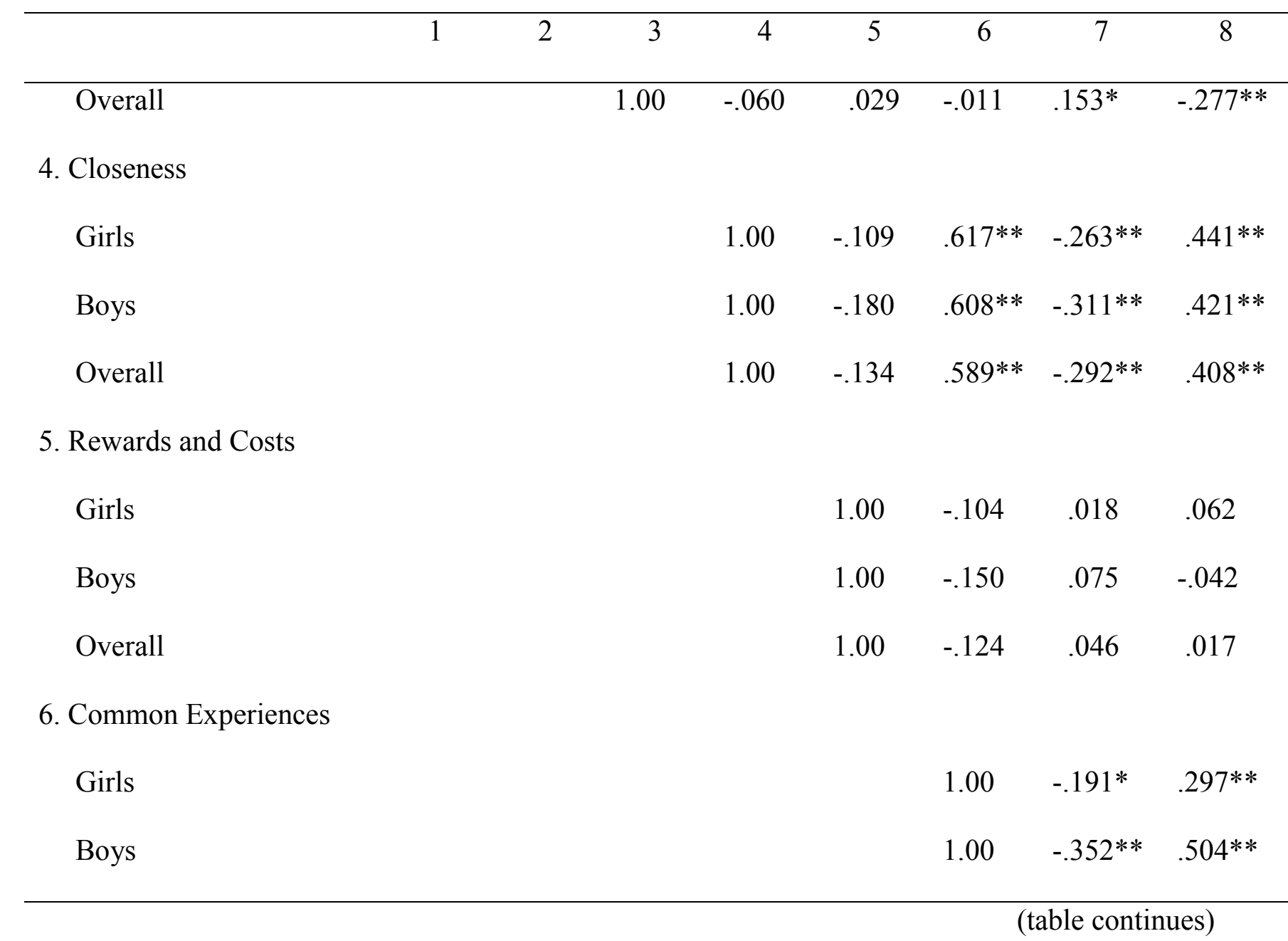


Table 2 (continued)

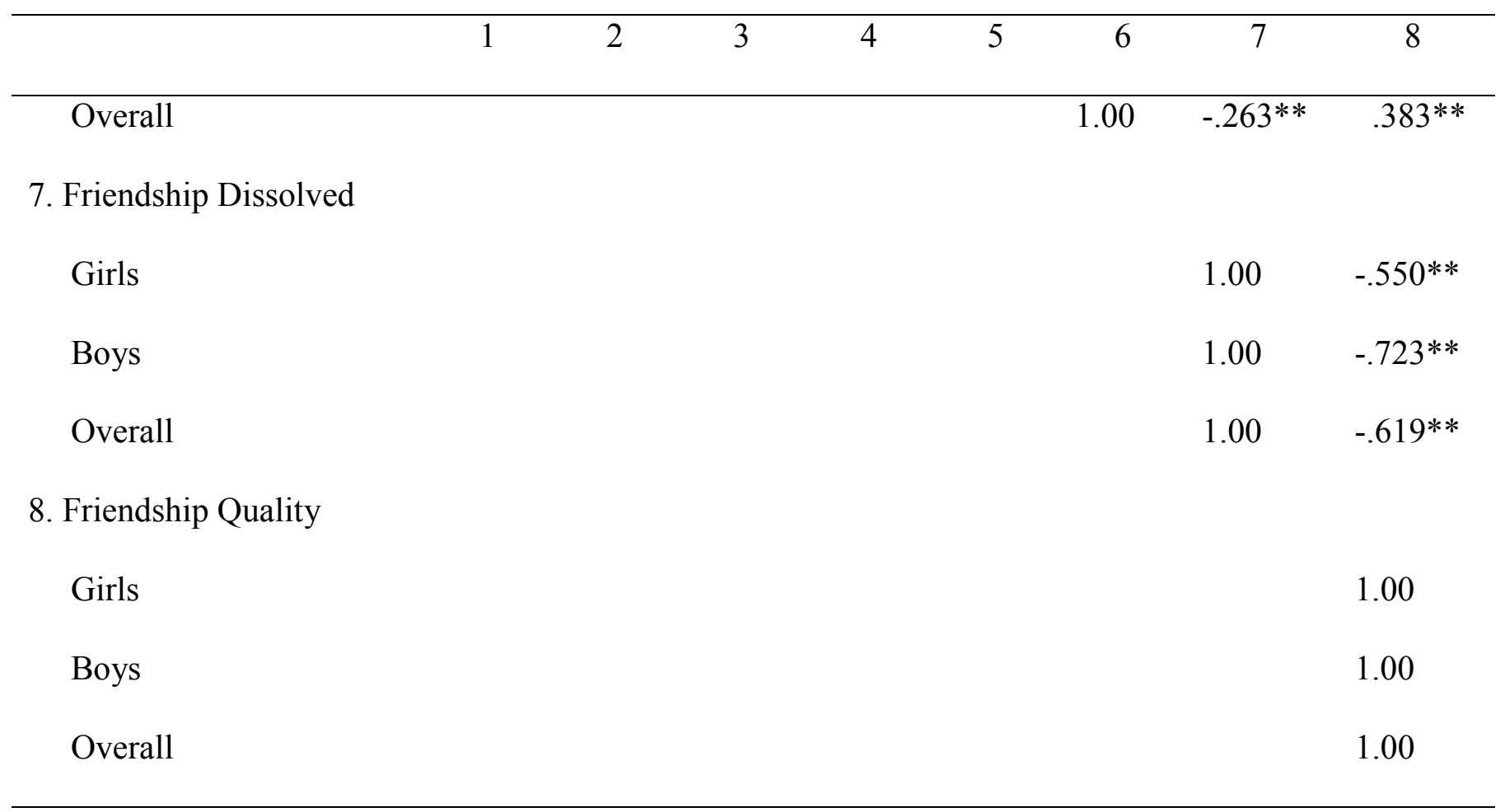

Note. ${ }^{*}$ indicates a significant correlation at the 0.05 level

$* *$ indicates a significant correlation at the 0.01 level 
Table 3

Logistic Regression Analysis Predicting Friendship Dissolution from Six Friendship Features

\begin{tabular}{lcccccc}
\hline Variable & $B$ & S. E. & Wald & $d f$ & $p$ & Exp (B) \\
\hline Length of Friendship & -.170 & .084 & 4.080 & 1 & $.043^{*}$ & .844 \\
Closeness & -.237 & .302 & .615 & 1 & .433 & .789 \\
Common Experiences & .270 & .288 & .878 & 1 & .349 & 1.310 \\
Balance of Costs and Rewards & -.042 & .208 & .042 & 1 & .838 & .958 \\
Personal Characteristics & -.933 & .268 & 12.078 & 1 & $.001 *$ & .393 \\
Ease of Finding a New Friend & .413 & .229 & 3.263 & 1 & .071 & 1.511 \\
\hline Note. $*$ indicates a significant effect, $p<.05$. & & & & & &
\end{tabular}


Table 4

Logistic Regression Analysis Predicting Girls' Friendship Dissolution from Six Friendship Features

\begin{tabular}{llllllr}
\hline Variable & $B$ & $S . E$. & Wald & $d f$ & $p$ & Exp (B) \\
\hline Length of Friendship & -.362 & .143 & 6.383 & 1 & $.012^{*}$ & .696 \\
Closeness & .109 & .476 & .052 & 1 & .819 & 1.115 \\
Common Experiences & .222 & .404 & .303 & 1 & .582 & 1.249 \\
Balance of Costs and Rewards & -.251 & .369 & .462 & 1 & .497 & .778 \\
Personal Characteristics & -.997 & .421 & 5.606 & 1 & $.018^{*}$ & .369 \\
Ease of Finding a New Friend & .511 & .365 & 1.962 & 1 & .161 & 1.666 \\
\hline Note. $*$ indicates a significant effect, $p<.05$. & & & & & &
\end{tabular}


Table 5

Logistic Regression Analysis Predicting Boys' Friendship Dissolution from Six Friendship Features

\begin{tabular}{lcccccr}
\hline Variable & $B$ & $S . E$. & Wald & $d f$ & $p$ & Exp (B) \\
\hline Length of Friendship & .021 & .129 & .027 & 1 & .869 & 1.022 \\
Closeness & -.612 & .495 & 1.533 & 1 & .216 & .542 \\
Common Experiences & .164 & .479 & .117 & 1 & .733 & 1.178 \\
Balance of Costs and Rewards & -.106 & .284 & .139 & 1 & .709 & .899 \\
Personal Characteristics & -1.049 & .398 & 6.944 & 1 & $.008 *$ & .350 \\
Ease of Finding a New Friend & .500 & .349 & 2.059 & 1 & .151 & 1.649 \\
\hline Note. ${ }^{*}$ indicates a significant effect, $p<.05$. & & & & & &
\end{tabular}


Table 6

Standardized and Unstandardized Regression Weights for Models Predicting Overall Friendship Quality From Friendship Features

\begin{tabular}{|c|c|c|c|c|c|c|c|}
\hline Variables & $B$ & $S E B$ & $\beta$ & $R^{2}$ & $F$ & $d f$ & $p$ \\
\hline Overall Model & & & & .322 & 14.014 & 6,177 & $.000^{*}$ \\
\hline Length of Friendship & .011 & .032 & .023 & & & & .723 \\
\hline Closeness & .173 & .126 & .116 & & & & .172 \\
\hline Common Experiences & .140 & .118 & .099 & & & & .238 \\
\hline Balance of Costs and Rewards & .090 & .089 & .063 & & & & .313 \\
\hline Personal Characteristics & .469 & .119 & .342 & & & & $.000 *$ \\
\hline Ease of Finding a New Friend & -.303 & .083 & -.227 & & & & $.000 *$ \\
\hline Girls & & & & .259 & 7.295 & 6,102 & $.000 *$ \\
\hline Length of Friendship & .018 & .043 & .037 & & & & .666 \\
\hline Closeness & .382 & .189 & .259 & & & & $.046^{*}$ \\
\hline Common Experiences & .036 & .160 & .025 & & & & .820 \\
\hline Balance of Costs and Rewards & .152 & .133 & .097 & & & & .257 \\
\hline Personal Characteristics & .283 & .179 & .207 & & & & .118 \\
\hline Ease of Finding a New Friend & -.335 & .114 & -.253 & & & & $.004 *$ \\
\hline Boys & & & & .383 & 8.661 & 6,68 & $.000^{*}$ \\
\hline Length of Friendship & -.031 & .053 & -.062 & & & & .564 \\
\hline
\end{tabular}


Table 6 (continued)

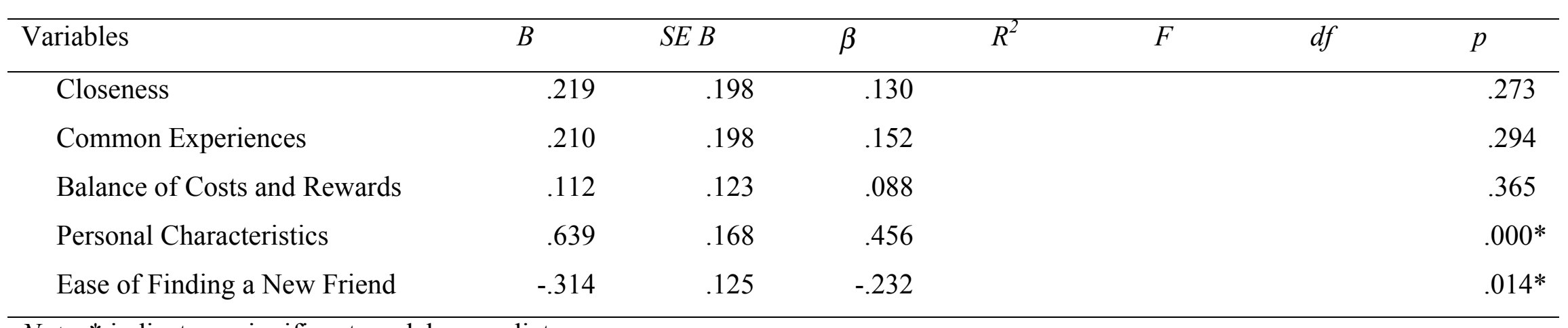

Note. * indicates a significant model or predictor 
Table 7

Percentages of Participants Who Identified Various Causes of Problems and Friendship Endings

Cause of Problem Cause of Friendship Ending

Causes

Communication

Total

13.5

Girls

Boys

13.6

1.5

Support and Resources

Total

Girls

Boys

Trust

Total

Girls

Boys

Group Membership

Total

21.2

22.1

19.7

17.1

22.1

9.1

Girls

Boys
6.5

11.8

12.5

10.6
22.4

19.7 
Table 7 (continued)

Cause of Problem Cause of Friendship Ending

Causes

Common Experiences

Total

Girls

Boys

Personal Characteristics

Total

Girls

Boys

Other or Unsure

Total

12.9

13.5

12.1

20.6

19.2

22.7

Girls

Boys

1.2

0

3.0
34.7

30.8

40.9

20.0

21.2

18.2

40.9

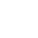




\section{Figure Caption}

Figure 1. Percentages of reported causes of problems and causes of friendship dissolution. 


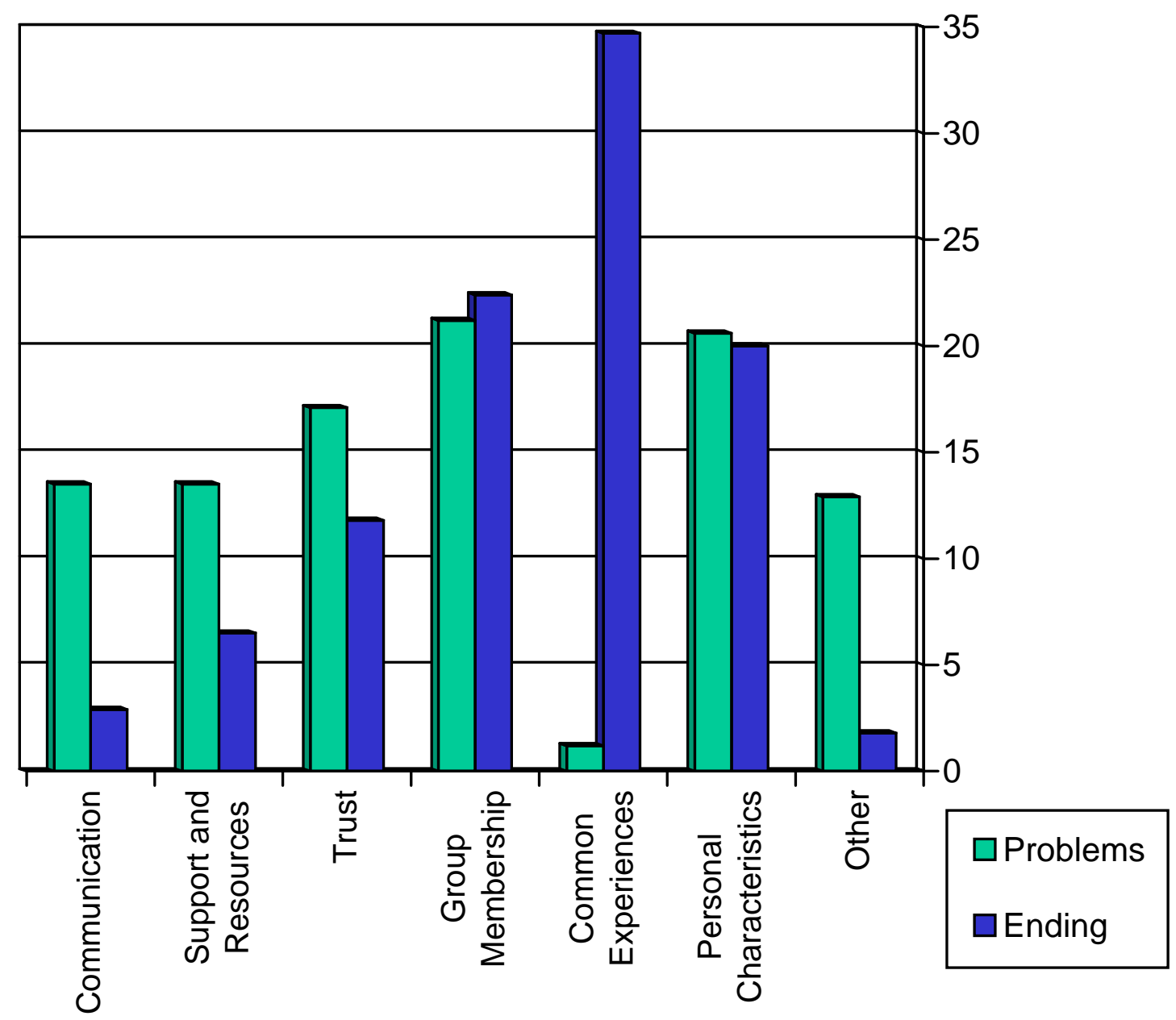

